\title{
Dynamic structure mediates halophilic adaptation of a DNA polymerase from the deep-sea brines of the Red Sea
}

\author{
Masateru Takahashi, ${ }^{*}$ Etsuko Takahashi, ${ }^{*}$ Luay I. Joudeh, ${ }^{*}$ Monica Marini, ${ }^{\dagger}$ Gobind Das, ${ }^{\dagger}$ \\ Mohamed M. Elshenawy, ${ }^{*}$ Anastassja Akal, ${ }^{+\neq}$Kosuke Sakashita, ${ }^{*}$ Intikhab Alam, ${ }^{\S}$ Muhammad Tehseen, ${ }^{*}$ \\ Mohamed A. Sobhy, ${ }^{*}$ Ulrich Stingl, $\left.{ }^{*}, \pi\right]$ Jasmeen S. Merzaban, ${ }^{*}$ Enzo Di Fabrizio, ${ }^{+}$and Samir M. Hamdan ${ }^{*, 1}$ \\ *Biological and Environmental Science and Engineering Division, ${ }^{\dagger}$ Physical Science and Engineering Division, ${ }^{\ddagger}$ KAUST Catalysis Center, and \\ ${ }^{\S}$ Computational Bioscience Research Center, King Abdullah University of Science and Technology, Jeddah, Saudi Arabia; and ${ }^{\top}$ Fort Lauderdale \\ Research and Education Center, University of Florida, Davie, Florida, USA
}

\begin{abstract}
The deep-sea brines of the Red Sea are remote and unexplored environments characterized by high temperatures, anoxic water, and elevated concentrations of salt and heavy metals. This environment provides a rare system to study the interplay between halophilic and thermophilic adaptation in biologic macromolecules. The present article reports the first DNA polymerase with halophilic and thermophilic features. Biochemical and structural analysis by Raman and circular dichroism spectroscopy showed that the charge distribution on the protein's surface mediates the structural balance between stability for thermal adaptation and flexibility for counteracting the salt-induced rigid and nonfunctional hydrophobic packing. Salt bridge interactions via increased negative and positive charges contribute to structural stability. Salt tolerance, conversely, is mediated by a dynamic structure that becomes more fixed and functional with increasing salt concentration. We propose that repulsive forces among excess negative charges, in addition to a high percentage of negatively charged random coils, mediate this structural dynamism. This knowledge enabled us to engineer a halophilic version of Thermococcus kodakarensis DNA polymerase.-Takahashi, M., Takahashi, E., Joudeh, L. I., Marini, M., Das, G., Elshenawy, M. M., Akal, A., Sakashita, K., Alam, I., Tehseen, M., Sobhy, M. A., Stingl, U., Merzaban, J. S., Di Fabrizio, E., Hamdan, S. M. Dynamic structure mediates halophilic adaptation of a DNA polymerase from the deep-sea brines of the Red Sea. FASEB J. 32, 3346-3360 (2018). www.fasebj.org
\end{abstract}

KEY WORDS: DNA polymerase engineering · halophilic enzymes · thermophilic enzymes $\cdot$ structure dynamism · structural adaptation

The deep-sea anoxic brines of the Red Sea are considered among the most remote, challenging, and extreme environments on earth. Approximately 25 such brine-filled pools have been discovered in the Red Sea (1-3), all of which are

ABBREVIATIONS: BR3 Pol, brine pool-3 polymerase; CD, circular dichroism; dNTP, deoxynucleotide triphosphate; dsDNA, double-stranded DNA; KOD, Thermococcus kodakarensis; ORF, open reading frame; Pfu, Pyrococcus furiosus; RU, response unit; SPR, surface plasmon resonance; ssDNA, single-stranded DNA; TBP, TATA box-binding protein; WT, wild type; yPolD, yeast DNA polymerase $\delta$

${ }^{1}$ Correspondence: Biological and Environmental Science and Engineering Division, King Abdullah University of Science and Technology (KAUST), Building 2-4221, Thuwal, Jeddah, Saudi Arabia. E-mail: samir. hamdan@kaust.edu.sa

This is an Open Access article distributed under the terms of the Creative Commons Attribution 4.0 International (CC BY 4.0) (http:// creativecommons.org/licenses/by/4.0/) which permits unrestricted use, distribution, and reproduction in any medium, provided the original work is properly cited.

doi: $10.1096 /$ fj.201700862RR

This article includes supplemental data. Please visit $h t t p: / / w w w$.fasebj.org to obtain this information. anoxic and highly saline deep-seawater pools with elevated temperatures and heavy metal ion concentrations. In contrast to numerous geological and geochemical studies of the brine pools, very few studies have focused on the microbiology of deep-sea brines (4). Novel culture-independent techniques, accompanied by traditional culture-based studies, have revealed an unexpected and enormous biodiversity in the local microbial communities of the brine pools and have identified several new groups of extremophilic microorganisms (5-7). The adaptive mechanisms of biologic macromolecules in these microorganisms remain uncharacterized. Given that DNA-binding proteins require positively charged residues to interact with the negative charges on DNA phosphate groups, we wondered how DNA-processing enzymes in these microorganisms interact with DNA at elevated salt concentrations.

Indeed, salt has significant effects on the solubility, stability, and conformation of proteins and is likely to influence their function $(8,9)$. Water hydrates surfaceexposed charged residues to enhance protein solubility. In addition, water cages solvent-exposed hydrophobic 
patches, which play a critical role in folding the protein into its functional form (10). When present, salt strengthens hydrophobic packing and contributes to protein folding; however, elevated salt concentrations sequester water molecules from solvent-exposed hydrophobic patches, possibly promoting rigid and nonfunctional hydrophobic packing and protein aggregation $(10,11)$. Halophilic proteins may overcome such salt-induced hydrophobic packing by increasing the hydrophilicity and decreasing the hydrophobicity of their surfaces (12-15). Increasing the number of negatively charged residues (Asp and Glu) could improve the hydrophilicity of the surface. Asp and Glu have great capacity to bind water molecules and utilize salts by binding hydrated cations (12-18). Decreasing the number of hydrophobic residues with bulky side chains (Phe, Ile, and Leu) rather than those with small side chains (Gly, Ala, Ser, and Thr) might reduce surface hydrophobicity $(14,19)$. Salt bridges between surfaceexposed, oppositely charged residues could also influence the stability and folding of halophilic proteins $(20,21)$. Collectively, these previous findings suggest that halophilic proteins may be overly flexible at low salt concentrations and consequently less active, which may explain their increased activity at higher salt concentrations.

The structural requirements of thermophilic proteins, conversely, are likely to be opposite those of halophilic proteins. Strong hydrophobic packing through hydrophobic residues with bulky side chains and salt bridge interactions between oppositely charged residues might be the key mechanisms that increase the stability of thermophilic proteins $(22,23)$. The simultaneous increase in both temperature and salt concentrations in the deep-sea brines in the Red Sea suggests that proteins in extremophilic microorganisms paradoxically adapt to 2 environments with opposite structural requirements.

Little is known about how halophilic DNA-binding proteins interact with DNA. Analysis of the surface charges combined with site-directed mutagenesis among halophilic and mesophilic transcription factors [TATA box-binding proteins (TBPs)] showed that halophilic TBP increases the number of negatively charged residues in the DNA-binding region. These charges may sequester positive ions into the DNA-binding region, allowing indirect interaction with the DNA via salt bridges. This indirect interaction could support DNA binding at elevated salt concentrations $(24,25)$. However, enzymes involved in genomic DNA replication and maintenance often experience conformational changes and induce changes in the DNA structure for catalysis. We therefore analyzed how indirect interactions with DNA support the functioning of halophilic DNA-binding enzymes, such as DNA polymerases, under hypersaline conditions.

Characterization of a polymerase, termed brine pool-3 polymerase (BR3 Pol), from archaea that thrive at temperatures approaching $\sim 55^{\circ} \mathrm{C}$ demonstrated unusual tolerance to high salt and metal ion concentrations and a unique ability to use $\mathrm{Zn}^{2+}$ ions effectively as cofactors. These observations suggested that structural adaptation is required in the proteins of brine pool microorganisms. The simultaneous adaptation to high temperature and high salt concentration is mediated by increasing salt bridge interactions that enhance structural stability, whereas dynamic fluctuation is maintained by a high percentage of negatively charged random coils. Functional and Raman analyses revealed that the structure becomes more fixed and functional with increasing salt concentration. We also found that the polymerase is likely to maintain the conserved direct interaction mode with DNA. Our results suggest that catalysis in halophilic DNA polymerases relies on direct DNA interactions, whereas the structural flexibility that counteracts salt-induced, rigid, and hydrophobic packing allows active conformation in a wide range of salt concentrations.

\section{MATERIALS AND METHODS}

\section{Enzymes}

We deposited the cDNA fragment corresponding to BR3 Pol in GenBank under accession number KXB03331. To amplify the open reading frame (ORF) region by PCR [Thermococcus kodakarensis (KOD) polymerase], single amplified genomic DNA samples were used as templates with primers (5'-CACCATGGCAAATCAGACAACAAATGG-3' and 5'-TTATTTGAATTTTCCGAGTTTTACTTGTCG-3') (26). The thermal cycler program used for PCR reactions consisted of a predenaturing step $\left(94^{\circ} \mathrm{C}\right.$ for $2 \mathrm{~min})$, a denaturing step $\left(94^{\circ} \mathrm{C}\right.$ for $\left.15 \mathrm{~s}\right)$, an annealing step $\left(56^{\circ} \mathrm{C}\right.$ for $\left.30 \mathrm{~s}\right)$, and an extension step $\left(68^{\circ} \mathrm{C}\right.$ for $\left.2 \mathrm{~min}\right)$. The denaturing to extension steps were repeated 29 times. The resulting clone was sequenced and showed 9-aa insertion at $\mathrm{N}$ terminus compared with the published sequence in the database. We added this insertion to the ORF and cloned it into the pENTR/D-TOPO vector (Thermo Fisher Scientific, Waltham, MA, USA). The ORF of BR3 Pol identified from the single amplified genome was transferred to the pDEST17 vector (Thermo Fisher Scientific) by using the LR Clonase II enzyme mix (Thermo Fisher Scientific). BR3 Pol was overexpressed in Escherichia coli Rosetta 2(DE3) (Novagen, Stamford, CT, USA) and transformed with the pDEST17/BR3 plasmid. Overexpression was induced by the addition of isopropyl $\beta$-D-1-thiogalactopyranoside (final concentration, $1 \mathrm{mM}$ ), and cells were harvested after $3 \mathrm{~h}$ of incubation.

The collected cells were resuspended in lysis buffer $(10 \mathrm{mM}$ Tris$\mathrm{HCl} \mathrm{pH} \mathrm{8.0,} 80 \mathrm{mM} \mathrm{KCl}, 5 \mathrm{mM} 2-\mathrm{ME}, 1 \mathrm{mM}$ EDTA) and incubated on ice with lysozyme (final concentration, $1 \mathrm{mg} / \mathrm{ml}$ ) for $60 \mathrm{~min}$ and then disrupted by sonication. The crude extract was centrifuged to remove cell debris, and the collected supernatant was subjected to ammonium sulfate precipitation at $70 \%$ saturation. The pellet obtained from ammonium sulfate precipitation was dissolved in Buffer A (50 mM Tris- $\mathrm{HCl}$ pH 8.0, $500 \mathrm{mMNaCl}$ ) and loaded onto a Sephacryl Sepharose column (GE Healthcare, Waukesha, WI, USA). The flow-through fractions containing BR3 Pol were collected and loaded into a HisTrap HP $5 \mathrm{ml}$ column (GE Healthcare) in which a gradient against Buffer B $(10 \mathrm{mM}$ Tris- $\mathrm{HCl} \mathrm{pH}$ 8.0, $50 \mathrm{mM} \mathrm{KCl}, 500 \mathrm{mM}$ imidazole) eluted the bound proteins. The BR3 Pol-containing fractions were collected and passed through a HiTrap Heparin $1 \mathrm{ml}$ column (GE Healthcare) in which a gradient against Buffer C (10 mM Tris- $\mathrm{HCl}$ pH 8.0, $1 \mathrm{M} \mathrm{KCl})$ eluted the bound proteins. The BR3 Pol-containing fractions were dialyzed against Buffer D (50 mM Tris- $\mathrm{HCl}$ pH 7.5, $50 \mathrm{mM} \mathrm{KCl,} 1 \mathrm{mMDTT}$, $0.1 \%$ Tween $20,50 \%$ glycerol). The protein concentration was determined by absorbance at $280 \mathrm{~nm}$. ProtParam software (Swiss Institute of Bioinformatics, Lausanne, Switzerland; https://web. expasy.org/protparam/was used to calculate the extinction coefficient of BR3 Pol based on the amino acid sequence composition (27).

pCold/KODWT plasmid to express N-terminal his-tagged KOD wild type (WT) was kindly given by Dr. Takahiro Kusakabe (Kyushu University, Fukuoka, Japan). KOD $\mathrm{KOD}_{\mathrm{BR} 3 \text { fingers, }}$ and $\mathrm{KOD}_{\mathrm{BR} 3 \text { thumb }}$ were constructed by using Gibson Assembly (New England Biolabs, Ipswich, 
MA, USA). The primers for KOD and the exonuclease domain of BR3 assembly to make $\mathrm{KOD}_{\text {BR3exo }}$ were BR3exo1: 5'-CAAAGGTCTGGTTCCGATGGAAGCAGACGAAGAACTCAATATCC-3'; BR3exo2: 5'-AGCTGAGCTTCCATCGGCAGTATTTCAGTGCCTAGCTCTAGAGTTG-3'; KOD1: 5'TTCCATCGGAACCAGACCTTTG-3'; and KOD2: 5'-CTGCCGATGGAAGCTCAGCTGTC-3'. The primers for KOD and the fingers domain of $\mathrm{BR} 3$ assembly to make $\mathrm{KOD}_{\mathrm{BR} 3 \text { fingers }}$ were BR3fingers1: 5'-GTTTCTGCAAAGACTTCCCGGGTTTCATTCCGGAGACATTGAAAG-3'; BR3fingers2: $5^{\prime}$ GCAGTACCAACGAGCACGAGCGTATCCAAGCATCCCATAGAATGAGTTC-3'; KOD3: 5'-CGGGAAGTCTTTGCAGAAACG-3'; and KOD4: 5'-GCTCGTGCTCGTTGGTACTG-3'. The primers for KOD and the thumb domain of BR3 assembly to

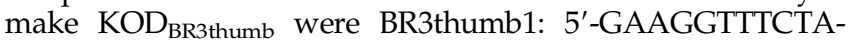
CAAGCGTGGCGTATTCGTCACCAAAAAAAGATACGCAATG-3'; BR3thumb2: 5'-TGGGTCGGCGCGCCCACCCTTTTATTTGAATTTTCCGAGTTTTACTTGTCGC-3'; KOD5: 5'-GCCACGCTTGTAGAAACCTTC-3'; and KOD6: 5'-AAGGGTGGGCGCGCCG-3'.

The KOD chimera proteins were overexpressed in E coli BL21 (DE3) pLysS (Novagen). The transformed cells were incubated at $37^{\circ} \mathrm{C}$ to grow, and after cooling down the temperature to $16^{\circ} \mathrm{C}$, isopropyl $\beta$-D-1-thiogalactopyranoside (final concentration, $1 \mathrm{mM}$ ) was added to induce the overexpression. The cells were incubated at $16^{\circ} \mathrm{C}$ for $6 \mathrm{~h}$ and harvested. The collected cells were dissolved in lysis buffer $(10 \mathrm{mM}$ Tris- $\mathrm{HCl} \mathrm{pH}$ 8.0, $80 \mathrm{mM}$ $\mathrm{KCl}, 5 \mathrm{mM}$ 2-ME, $1 \mathrm{mM}$ EDTA) and incubated on ice with lysozyme (final concentration, $1 \mathrm{mg} / \mathrm{ml}$ ) for $60 \mathrm{~min}$ and then disrupted by sonication. The crude extract was centrifuged to remove cell debris, and the collected supernatant was subjected to ammonium sulfate precipitation at $70 \%$ saturation. The pellet obtained from ammonium sulfate precipitation was dissolved in Buffer A (50 mM Tris- $\mathrm{HCl} \mathrm{pH} \mathrm{8.0,500} \mathrm{mM} \mathrm{NaCl)} \mathrm{and} \mathrm{loaded} \mathrm{into}$ a HisTrap FF 5-ml (GE Healthcare) in which a gradient against Buffer B (10 mM Tris-HCl pH 8.0,50 mM KCl, 500 mMimidazole) eluted the bound proteins. The KOD chimera protein-containing fractions were collected and passed through a HisTrap Heparin 1-ml column (GE Healthcare) in which a gradient against Buffer $F$ (20 mM Tris- $\mathrm{HCl} \mathrm{pH}$ 8.0, $10 \mathrm{mM}$ 2-ME, $1 \mathrm{M} \mathrm{NaCl}$ ) eluted the bound proteins. The KOD chimera protein-containing fractions were dialyzed against Buffer $\mathrm{G}(50 \mathrm{mM}$ Tris- $\mathrm{HCl} \mathrm{pH}$ 8.0, $0.1 \mathrm{mM}$ EDTA, $0.1 \mathrm{mM}$ DTT, $0.1 \%$ NP-40, 0.1\% Tween $20,50 \%$ glycerol). The protein concentration was determined by absorbance at $280 \mathrm{~nm}$ using the extinction coefficient and MW calculated based on the amino acid sequence composition of KOD chimera proteins by using ProtParam software (27).

\section{Predictions of disordered regions in proteins}

The probability of disorder was calculated by using Regional Order Neural Network (RONN) software (https://www.strubio.ox. ac.uk/RONN) (28-30).

\section{Raman spectroscopy}

Five-microliter solutions of each sample were drop-casted on $\mathrm{CaF}_{2}$ substrates (Crystran, Poole, United Kingdom) and investigated with a WITec confocal Raman system (WITec Instruments, Knoxville, TN, USA), equipped with a 532-nm laser and a $\times 100$ objective, working at a laser power of $1.32 \mathrm{~mW}$ with a 600 line $/ \mathrm{mm}$ grating. The measurements were conducted in the back-scattering configuration and performed in the liquid state. Data analysis was performed by using $\sim 10$ spectra obtained on different points of the droplet. Measurements were performed at room temperature $\left(21^{\circ} \mathrm{C}\right)$ and $53 \%$ relative humidity. Data analysis was performed by using WITec Project 4 software (WITec Instruments.).

\section{Circular dichroism spectroscopy analysis}

Circular dichroism (CD) measurements were performed at wavelengths from 200 to $250 \mathrm{~nm}$ at $20^{\circ} \mathrm{C}$ using $1 \mathrm{~nm}$ intervals with 10 accumulations per read. The proteins were diluted to a final concentration of $3 \mu \mathrm{M}$ (BR3 Pol) and $1.3 \mu \mathrm{M}$ (KOD Pol) in PBS buffer containing the corresponding salt concentrations and incubated at room temperature for $5 \mathrm{~min}$ before the measurements. A sample volume of $300 \mu \mathrm{l}$ was used in a $0.1-\mathrm{cm}$ quartz cuvette (Hellma, Huntington, NY, USA), and the measurement was performed on a Jasco J-815 Spectrometer (Jasco, Easton, MD, USA). The molar ellipticity was calculated by Spectra Manager II (Jasco).

\section{Primer extension assays}

The polymerase activity was measured by using primer extension assays, which were conducted as previously described (31) with the following modifications. A 35-mer template was annealed to a 15-mer Cy3-labeled primer. The primer extension assays were performed in a reaction buffer containing $20 \mathrm{mM}$ Tris-HCl pH 8.8, $10 \mathrm{mM}\left(\mathrm{NH}_{4}\right)_{2} \mathrm{SO}_{4}, 0.1 \%$ Triton X-100, $200 \mu \mathrm{M}$ deoxynucleotide triphosphates (dNTPs), $50 \mathrm{mM} \mathrm{KCl}$, and $2 \mathrm{mM} \mathrm{MgSO}_{4}$ at $45 \mathrm{C}^{\circ}$ for $4 \mathrm{~min}$ and stopped with EDTA (final concentration, $100 \mathrm{mM} \mathrm{pH} 8.0$ ). The same reaction buffer without salt and/or metal ions was used for the assays with various types and concentrations of salts and metal ions as specified in the figure legends. The reactions were terminated by EDTA (final concentration, $100 \mathrm{mM} \mathrm{pH} \mathrm{8.0).} \mathrm{The} \mathrm{synthesized} \mathrm{products} \mathrm{were}$ loaded on $20 \%$ polyacrylamide $/ 7.5 \mathrm{M}$ urea/1× TBE denaturing gel, and the gel was visualized by using Typhoon Trio (GE Healthcare). Each experiment was performed at least 3 times to confirm reproducibility.

\section{Single-molecule primer extension assays}

The primed single-stranded DNA (ssDNA) was generated by annealing M13mp18 ssDNA (New England Biolabs, Ipswich, MA, USA) to 100-fold excess of the 5'-Dig-CTAGAGGATCCCCGGGTACCGAGCTCGAATTCGTAATCA-Bio-TGGTCATAGCTGTTTCCTGTGTG-3' primer (Integrated DNA Technologies, Coralville, IA, USA). Annealed DNA was linearized with EcoRI (New England Biolabs), and the reaction was stopped by EDTA (final concentration, $10 \mathrm{mM} \mathrm{pH} \mathrm{8.0).} \mathrm{EcoRI} \mathrm{was} \mathrm{inactivated} \mathrm{by}$ heating the solution at $65^{\circ} \mathrm{C}$ for $20 \mathrm{~min}$. Excess unannealed primer and heat-inactivated EcoRI were removed by using a $100 \mathrm{kD}$ Amicon centrifugal filter device (EMD Millipore, Billerica, MA, USA). The final concentration of the DNA was quantified by using UV-visible absorption spectroscopy at 260 $\mathrm{nm}$ with an extinction coefficient of $91,801.1 \mathrm{mM} / \mathrm{cm}$.

Single-molecule experiments were performed at $37^{\circ} \mathrm{C}$ in a custom-built microfluidic flow cell as described previously (32, 33). Briefly, Pyrococcus furiosus (Pfu) Pol and BR3 Pol were introduced into the flow cell at $20 \mathrm{nM}$ concentration in a reaction buffer containing $20 \mathrm{mM}$ Tris- $\mathrm{HCl}$ pH 7.5, $5 \mathrm{mM} \mathrm{MgCl}_{2}, 5 \mathrm{mM}$ DTT, and $760 \mu \mathrm{M}$ dNTPs, with $250 \mathrm{mM} \mathrm{KCl}$ for BR3 Pol and $0 \mathrm{mM} \mathrm{KCl}$ for Pfu Pol. The replication reaction was performed under continuous presence of proteins in solution. Data acquisition and processing methods were essentially the same as described previously (34-36). Briefly, the centroid position of the beads during each acquisition time point (500-ms sampling rate) was determined by fitting a 2-dimensional gaussian distribution of the bead intensities by using the DiaTrack particle-tracking software (SemaSopht, North Epping, NSW, Australia). Residual instabilities in the flow were corrected by subtracting traces corresponding to tethered DNA molecules that were not enzymatically altered from all traces. Displacement of the beads due to 
the conversion of the template strand from ssDNA to doublestranded DNA (dsDNA) during primer extension was converted into numbers of synthesized nucleotides by using a calibration factor $(3.76 \mathrm{~b} / \mathrm{nm})$ that was derived from the difference in the length between ssDNA and dsDNA at the applied stretching force $(\sim 3 \mathrm{pN})(35-37)$. Pauses in DNA synthesis were defined as a minimum of 6 data points with no change in the DNA length with amplitude fluctuations $<3$ times the SD of the noise.

\section{Proofreading activity assays}

The proofreading activity assays were conducted as previously described (31) with the following modifications. A 35-mer template containing an internal EcoRI site was annealed to a 15-mer Cy3-labeled primer with $0,1,2$, or 3 mismatched nucleotides at the $3^{\prime}$ end for the proofreading assays (Supplemental Fig. 8A). The proofreading assays were performed in a reaction buffer containing $20 \mathrm{mM}$ Tris- $\mathrm{HCl} \mathrm{pH} 8.8,10 \mathrm{mM}\left(\mathrm{NH}_{4}\right)_{2} \mathrm{SO}_{4}, 0.1 \%$ Triton X-100, $200 \mu \mathrm{M} \mathrm{dNTPs}$, and $2 \mathrm{mMMgSO}_{4}$ at $45 \mathrm{C}^{\circ}$ for $4 \mathrm{~min}$ and stopped with EDTA (final concentration, $100 \mathrm{mM} \mathrm{pH} \mathrm{8.0).}$ The reaction products were denatured, and EDTA was removed; $5 \mathrm{U}$ of EcoRI was then added, followed by additional incubation at $37^{\circ} \mathrm{C}$ for $30 \mathrm{~min}$. The reactions were terminated by EDTA (final concentration, $100 \mathrm{mM} \mathrm{pH} \mathrm{8.0).} \mathrm{The} \mathrm{synthesized} \mathrm{products} \mathrm{in} \mathrm{the}$ proofreading assays were loaded on $20 \%$ polyacrylamide $/ 7.5 \mathrm{M}$ urea $/ 1 \times$ TBE denaturing gel, and the gel was visualized by using Typhoon Trio (GE Healthcare).

\section{PCR reactions}

The PCR reactions were performed in a reaction buffer containing $20 \mathrm{mM}$ Tris- $\mathrm{HCl} \mathrm{pH} 7.5,500 \mu \mathrm{M}$ dNTPs, $2 \mathrm{mM} \mathrm{MgCl}_{2}$ with various concentrations of $\mathrm{NaCl}$ and using $5 \mathrm{nM}$ protein concentration. pUC19 vector (New England Biolabs) was used as a template to amplify the ampicillin resistance gene with the following primers: 5' -TTACCAATGCTTAATCAGTGAGGCACC$3^{\prime}$ and $5^{\prime}$-ATGAGTATTCAACATTTCCGTGTCGCCC-3'. The thermal cycler program used for PCR reactions consisted of a predenaturing step $\left(94^{\circ} \mathrm{C}\right.$ for $\left.2 \mathrm{~min}\right)$, a denaturing step $\left(94^{\circ} \mathrm{C}\right.$ for $15 \mathrm{~s})$, an annealing step $\left(56^{\circ} \mathrm{C}\right.$ for $\left.30 \mathrm{~s}\right)$, and an extension step $\left(68^{\circ} \mathrm{C}\right.$ for $\left.1 \mathrm{~min}\right)$. These steps were repeated 29 times.

\section{Surface plasmon resonance binding}

Surface plasmon resonance (SPR) binding was performed by using a Biacore T100 label-free system (GE Healthcare). The system was washed twice with $1 \times$ HBS-EP buffer before DNA immobilization. The DNA constructs used in the analysis were ssDNA (5'-/Biotin/ TTTTTTTTTTTTTTTTTTTTTTTTTTTTTTTTTTTTTTTT-3'), primer/template strands (a template 5'-GAGGTGGCGTCGGGTGGACGGGTGGATTGAAATTTAGGCTGGCAC / Biotin/-3' annealed to 5-fold excess of non-biotinylated primer 5'-GTGCCAGCCTAAATTTCAATCC-3'), and dsDNA (the same template as in the primer/template strands DNA construct but annealed to 5-fold excess of non-biotinylated oligo 5'-GTGCCAGCCTAAATTTCAATCCACCCGTCCACCCGACGCCACCTC-3'). Annealing was performed in a buffer containing $20 \mathrm{mM}$ Tris- $\mathrm{HCl} \mathrm{pH} \mathrm{7.0,50} \mathrm{mM} \mathrm{NaCl}$ by heating at $90^{\circ} \mathrm{C}$ for $3 \mathrm{~min}$ and slowly cooling down to room temperature. A streptavidin sensor chip was activated by 3 injections of $50 \mathrm{mM}$ $\mathrm{NaOH}$ in $1 \mathrm{M} \mathrm{NaCl}$ followed by immobilizing the biotinylated DNA constructs at a flow rate of $10 \mu \mathrm{l} / \mathrm{min}$. The number of response units (RUs) for the immobilized DNA constructs was maintained between 75 and 150 depending on the MW of each substrate to ensure that the maximum RU from protein binding was $<500$. A control flow cell that was activated and blocked in the absence of protein or DNA was used to subtract the RU resulting from the nonspecific interactions with the sensor chip and the buffer's bulk refractive index. Before conducting the binding study, the system was primed twice with the corresponding binding buffer $(20 \mathrm{mM}$ Tris- $\mathrm{HCl} \mathrm{pH} 8.8,10 \mathrm{mM}$ $\left[\mathrm{NH}_{4}\right]_{2} \mathrm{SO}_{4}, 0.1 \%$ Triton $\mathrm{X}-100$, and the desired $\mathrm{NaCl}$ concentrations). In the binding study, serial dilutions of BR3 Pol, KOD Pol WT, KOD $\mathrm{BR}_{\mathrm{BR} \text { exo, }}$ and $\mathrm{KOD}_{\mathrm{BR} \text { thumb }}$ were made using the corresponding binding buffer. At each concentration, the run started with a surface-regeneration injection of the binding buffer in the presence of $1 \mathrm{M} \mathrm{NaCl}$ at a flow rate of $100 \mu \mathrm{l} / \mathrm{min}$ for $120 \mathrm{~s}$, followed by protein sample injection at a flow rate of $20 \mu \mathrm{l} / \mathrm{s}$ for $70 \mathrm{~s}$. The corrected sensorgrams were processed by using Biacore T100 Evaluation Software (GE Healthcare). The maximum RU reached at each protein concentration was fitted by using the steady-state affinity mode to obtain the equilibrium dissociation constant $\left(K_{d}\right)$ for each DNA substrate.

\section{RESULTS}

\section{Primary sequence characterization of BR3 Pol}

The archaeal species harboring BR3 Pol was identified from a water layer in the deep-sea brines with a temperature of $\sim 55^{\circ} \mathrm{C}$ and a salt concentration of $\sim 2.6 \mathrm{M}$ (unpublished results). We thus expected BR3 Pol to be both thermophilic and extremely halophilic. Sequence alignment of the dedicated 818 aa of BR3 Pol identified in INDIGO (6) with 3 extremely thermophilic archaeal DNA polymerases, KOD Pol, Pfu Pol, and Thermococcus litoralis (also known as Vent Pol), showed a high similarity of $\sim 45 \%$ (Supplemental Fig. 1). We therefore concluded that BR3 Pol is also a member of the family B DNA polymerases. Guided by the crystal structures of KOD Pol and Pfu Pol $(38,39)$, we defined 5 domains in BR3 Pol, including the N-terminal, exonuclease, palm, fingers, and thumb domains (Fig. 1A), which constitute the conserved and partially closed righthand feature that binds the primer/template strands.

The domains in BR3 Pol are largely conserved but display variation in the percentage of charged residues. Increasing the percentage of both negatively (Asp and Glu) and positively (Arg and Lys) charged residues to promote salt bridge interactions is a common adaptive mechanism in proteins from extreme thermophiles as well as in those from halophiles $(10,15,20)$. We found this scenario to be the case in BR3 Pol as well as in KOD Pol and Pfu Pol compared with a family B mesophilic polymerase represented here by the catalytic subunit of yeast DNA polymerase $\delta$ (yPolD) (Fig. 1B). However, unlike KOD Pol and Pfu Pol, which maintain a similar ratio of negatively-topositively charged residues as that in yPolD, BR3 Pol has more negatively charged residues (Fig. $1 B, C$ ). This outcome is consistent with the observation that halophilic proteins tend to have more negatively charged residues than mesophilic proteins $(13,15,18,19,40,41)$. Inserts with high Asp and/or Glu contents are a common feature in halophilic proteins $(15,42-44)$. In BR3 Pol, most acidic residues are distributed across the protein (Fig. $1 D$ and Supplemental Fig. 2) despite one of its two unique inserts being highly acidic (Supplemental Fig. 1).

Because there is no clear increase in the number of hydrophobic amino acids with large or small side chains over 
A

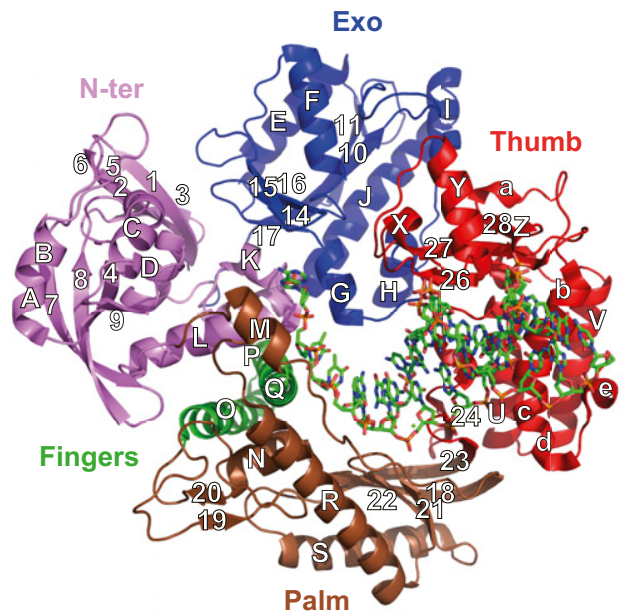

E

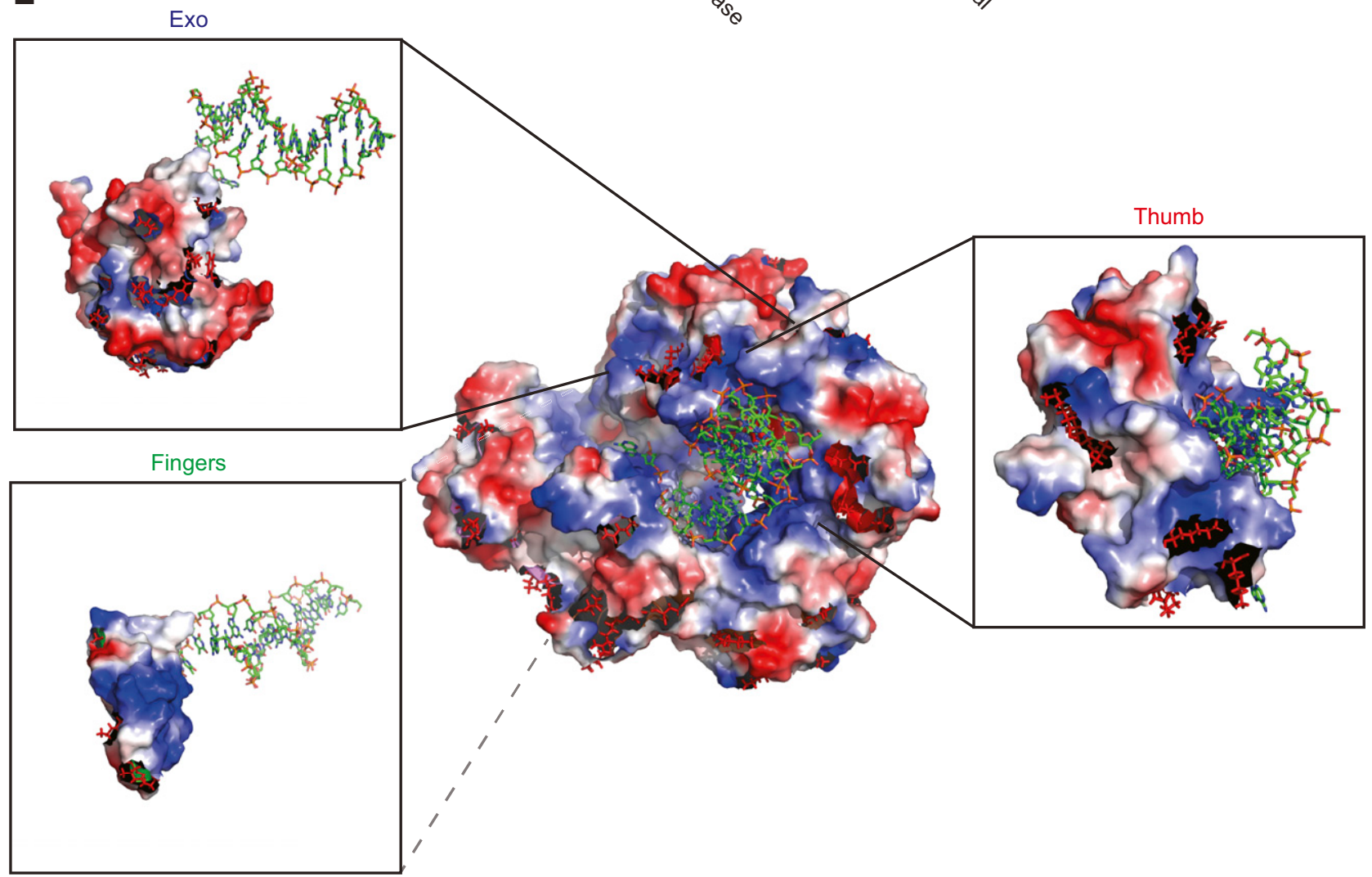

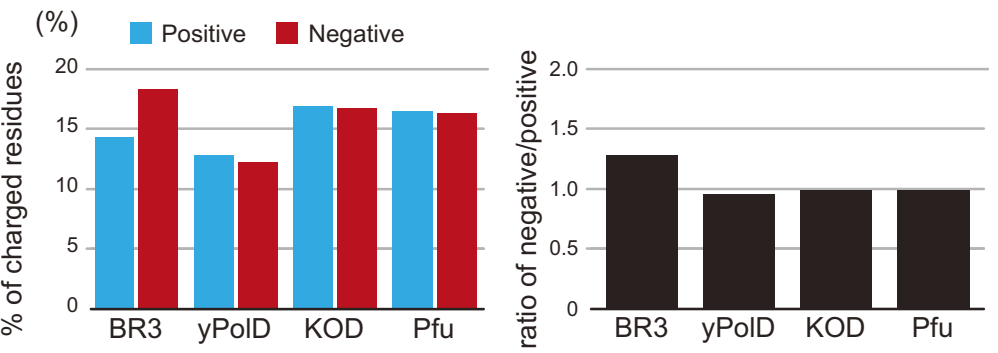

(fold)

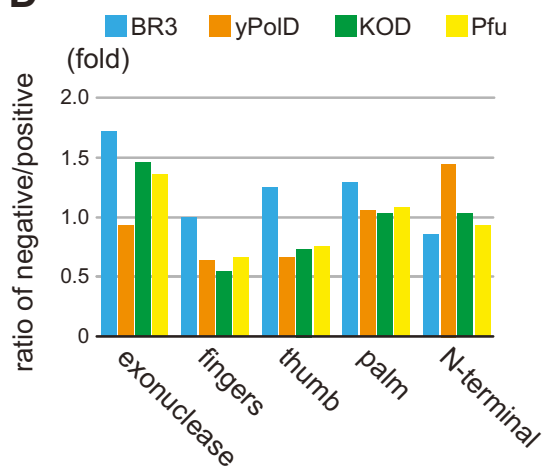

Figure 1. Primary sequence analysis of BR3 Pol. A) Structure of KOD Pol bound to DNA in the polymerization mode. The protein is depicted as a cartoon and DNA as sticks (PDB ID: 4K8Z) (46). The 5 domains in the polymerase and their secondary structure elements are colored as indicated. B) Traits of positively and negatively charged residues in BR3 Pol compared with the catalytic subunit of yPolD and to the archaeal polymerases KOD Pol and Pfu Pol. Percentages of positively charged residues (basic residues: Arg and Lys) and negatively charged residues (acidic residues: Glu and Asp) in BR3 Pol, yPolD, KOD Pol, and Pfu Pol are shown. C) Ratio of negatively charged to positively charged residues in BR3 Pol, yPolD, KOD Pol, and Pfu Pol. D) Ratio of negatively charged to positively charged residues for the 5 domains in the polymerase in BR3 Pol, yPolD, KOD Pol, and Pfu Pol. E) Molecular surface with electrostatic potential map in KOD Pol. The red and blue surfaces are acidic (negatively charged) and basic (positively charged) residues, respectively. The residues on the surface of KOD Pol that were replaced with unique acidic residues (Glu or Asp) in BR3 Pol on the surface are shown as red sticks. The electrostatic potential maps of the exonuclease, fingers, and thumb domains with DNA and the locations of unique acidic residues in BR3 Pol in each domain are highlighted. 
the number of such amino acids in mesophilic yPolD (Supplemental Fig. 2A), the contribution of hydrophobic packing to thermal stability in KOD Pol, Pfu Pol, and BR3 Pol is unclear. Disulfide bonds could be a key adaptive feature in extremely thermostable polymerases $(15,45)$. BR3 Pol retained its activity in temperatures up to $\sim 55^{\circ} \mathrm{C}$ (Supplemental Fig. 3A), and it is therefore classified as a thermophilic and not as an extremely thermophilic protein. BR3 Pol contains highly conserved Cys residues in the palm domain that have been proposed to create a disulfide bond in extremely thermophilic DNA polymerases (Supplemental Fig. 1) (38). KOD Pol and Pfu Pol, but not the extremely thermophilic polymerase T. litoralis Pol, have an extra disulfide bond in their palm domain. Introducing an equivalent disulfide bond in BR3 Pol, however, did not improve the protein activity at higher temperatures. Collectively, these results suggest that salt bridge interactions could be the major contributor to thermal stability in BR3 Pol. Salt tolerance, conversely, is likely mediated by excess negatively charged residues and structural stabilization via salt bridge interactions.

\section{Distribution of charged residues on the surface of BR3 Pol}

DNA polymerases from the B family, such as KOD Pol and Pfu Pol, have significant structural similarities $(38,39,46)$. We found high sequence homology between BR3 Pol and KOD Pol ( $\sim 45 \%)$. We also found that chimera proteins of KOD Pol containing exonuclease, fingers, or thumb domains of BR3 Pol displayed normal polymerization activity (as discussed later), suggesting that BR3 Pol is likely to have a high structural similarity to KOD Pol. We thus performed sequence alignment between BR3 Pol and KOD Pol and used the structure of KOD Pol bound to the DNA in the polymerization mode to provide reliable predictions on the location of the negatively and positively charged residues in BR3 Pol. We noticed that unique negatively charged residues in the fingers, exonuclease, and thumb domains of BR3 Pol would be positioned away from the DNA-binding crevice and toward its outer surface (Fig. $1 E$ and Supplemental Fig. 4). The thumb domain of KOD Pol contains 20 residues that are within $3.6 \AA$ of the DNA. Almost all of these residues are conserved in BR3 Pol (Supplemental Fig. 1). These observations suggest that the DNA-binding crevice is well conserved in BR3 Pol and that the increased negatively charged residues are primarily distributed across its surface.

\section{BR3 Pol has increased flexible regions}

We next obtained secondary structure information on purified recombinant BR3 Pol by using Raman spectroscopy. These measurements were performed with the protein in solution to maintain its native state. The secondary structure was estimated by fitting the spectral region of $1500-1800 \mathrm{~cm}^{-1}$ with 6 components of gaussianlorentzian mixed functions. The bands centered at $\sim 1550$, $1580,1610,1650,1670$, and $1680 \mathrm{~cm}^{-1}$ are associated with the indole ring of Trp, the combination of alanine and glycine, the combination of Tyr, Trp, and Phe, the $\alpha$-helix, the random coil and the $\beta$-sheet, respectively (47-49). Fitting of the secondary structure region of BR3 Pol with varying $\mathrm{NaCl}$ concentrations is shown in Supplemental Fig. 5A. With no salt, BR3 Pol contains a high percentage of random coils $(\sim 30 \%)$ (Fig. $2 A)$. In a side-by-side comparison, KOD Pol had 3-fold fewer random coils than BR3 Pol. These results are consistent with the prediction of intrinsic disorder by the RONN software (28-30), which showed an $\sim 30 \%$ disordered region in BR3 Pol (Fig. $2 B$ and Supplemental Fig. 6A). CD analysis also indicate that BR3 Pol has more random coil and $\beta$-sheet than KOD Pol because it has the less pronounced local minimum at $222 \mathrm{~nm}$, and its signal is upshifted between 208 and $222 \mathrm{~nm}$ compared with KOD Pol (Supplemental Fig. 6B) (50). RONN also predicted that $\mathrm{BR} 3 \mathrm{Pol}$ has the most disordered regions, followed by the mesophilic protein yPolD and then the extremely thermophilic proteins Pfu Pol and KOD Pol (Fig. 2B). We propose, therefore, that adaptation in halophilic proteins requires a flexible structure as opposed to the more rigid structure needed by extremely thermophilic proteins.

RONN analysis showed that the disordered regions in BR3 Pol were distributed across the entire protein (Supplemental Figs. 1 and 6A). Prediction of their locations based on the KOD Pol structure suggests that they should primarily be positioned on the protein's surface (Supplemental Figs. 1 and 4). Interestingly, RONN analysis suggested that 63 and $36 \%$ of the unique Asp and Glu residues, respectively, in BR3 Pol should be in these disordered regions (Supplemental Fig. 6C). It is unclear how Asp and Glu residues influence protein structure, but it has been suggested that Asp tends to act as an $\alpha$-helix breaker $(51,52)$ and exists more than Glu in the coiled regions of proteins (53). Halophilic proteins tend to have more Asp than Glu residues (54). In support of this suggestion, we found a strong correlation between the number of unique Asp residues and their presence in the disordered regions of BR3 Pol. We also suggest that the increased negative charges by both Asp and Glu residues may enhance the overall structural flexibility through repulsive forces.

\section{Salt induces transitioning in BR3 Pol from a dynamic to a more defined structure}

Raman spectroscopy was next used to investigate the effect of salt on the structure of BR3 Pol compared with KOD Pol. With increased $\mathrm{NaCl}$ concentration, we found that BR3 Pol and KOD Pol maintained their overall secondary structure composition (Fig. 2A). The CD spectrum of BR3 Pol and KOD Pol at different salt concentrations confirmed that minor changes occur in their secondary structures with elevated $\mathrm{NaCl}$ concentrations (Supplemental Fig. 6B). These results show that BR3 Pol is structurally adapted to resist hydrophobic packing by remaining flexible in a wide range of salt concentrations.

We next obtained structural information on hydroxyl group interactions by monitoring the hydrogen-bonding state of the phenolic $\mathrm{OH}$ group in BR3 Pol and KOD Pol at different $\mathrm{NaCl}$ concentrations by following the ratio of 
A

Figure 2. Protein structure analysis of BR3 Pol and KOD Pol. A) Percentages of $\alpha$-helices, random coils, and $\beta$-sheets in BR3 Pol (solid) and in KOD Pol (hatched) analyzed by using Raman spectroscopy. Supplemental Fig. $5 \mathrm{~A}$ illustrates fitting of the secondary structure region. The numbers above each bar indicate the value in a percentage, and SD is shown. $B$ ) Percentage of amino acids identified as a disordered region in BR3 Pol, KOD Pol, Pfu Pol, and yPolD. Disorder probability was calculated by RONN (28), and plots of disorder probability are presented in Supplemental Fig. 6A. C) Hydroxyl group interaction with hydrogen bonds of BR3 Pol and KOD Pol as a function of $\mathrm{NaCl}$ concentration. Supplemental Fig. $5 B$ illustrates curve fitting of the doublet of the Tyr band.

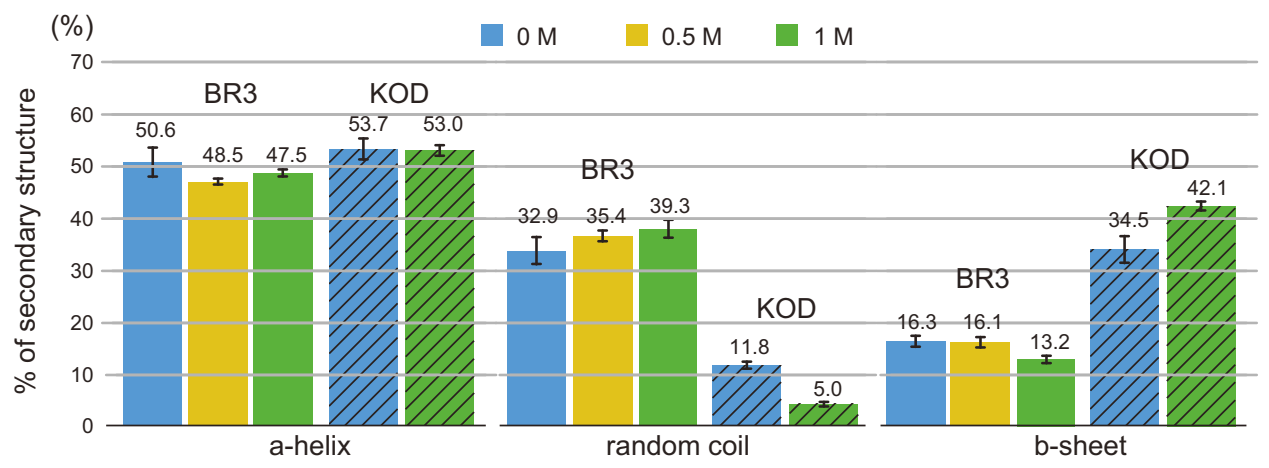

B

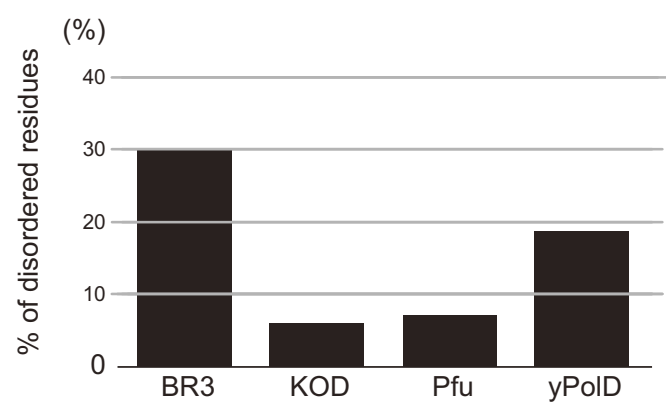

intensities of the Tyr doublet $\left(I_{850} / I_{830}\right)$. The ratio of intensities of the exposed Tyr doublet is a unambiguous marker of the hydrogen-bonding state of the phenolic $\mathrm{OH}$ group (55). $I_{850} / I_{830}$ for a solvent-exposed Tyr that forms hydrogen bonds with water is usually between 0.9 and 1.5 , whereas $I_{850} / I_{830}$ for a buried Tyr within the protein network that forms hydrogen bonds with Asp and Glu residues is $0.7-1.0$ (56). The ratio was calculated by integrating 2 peaks centered at 830 and $850 \mathrm{~cm}^{-1}$ in the spectral region of $800-880 \mathrm{~cm}^{-1}$ (Supplemental Fig. $5 B$ ); the same fitting criteria were used for KOD Pol. Overall, the phenolic hydroxyl groups of Tyr residues in BR3 Pol were stronger hydrogen bond acceptors than those in KOD Pol at all tested $\mathrm{NaCl}$ concentrations (Fig. 2C). This finding indicates that BR3 Pol can retain more water molecules than KOD Pol, presumably through its excess negatively charged residues that could interact directly with water and/or hydrated $\mathrm{Na}^{+}$ions. The hydroxyl group interactions in BR3 Pol, however, decreased when the $\mathrm{NaCl}$ concentration was increased to $0.5 \mathrm{M}$ before they started to increase again at an $\mathrm{NaCl}$ concentration of $1 \mathrm{M}$. Because the secondary structure was minimally influenced by salt, we interpreted the decreasing phase between 0 and $0.5 \mathrm{M}$ $\mathrm{NaCl}$ concentrations as reflecting a transition from a highly flexible and dynamic structure that rapidly exchanges water to a more defined structure that binds water and/or hydrated $\mathrm{Na}^{+}$ions in fixed positions. The increasing phase in the hydroxyl group interaction between 0.5 and $1 \mathrm{M} \mathrm{NaCl}$ concentration is more difficult to explain. We suspect that it might reflect the exchange of saturated protein-bound hydrated $\mathrm{Na}^{+}$ions with ions from the solution and/or from an increase in the dielectric constant of the excess negatively charged residues. The hydroxyl group interaction in KOD Pol, conversely, was weaker at $1 \mathrm{M}$ than at the no salt condition. Together, these results suggest that salt may induce rigid structural transitioning in KOD Pol as opposed to its dynamic structural transitioning in BR3 Pol.

\section{BR3 Pol tolerates high salt concentrations}

We next characterized the effect of salt on the polymerization activity of BR3 Pol and directly compared it with purified KOD Pol and Pfu Pol. The activity of BR3 Pol gradually increased with increasing salt concentration and approached its maximum at $0.5 \mathrm{M} \mathrm{NaCl}$ before it quickly declined at $0.75 \mathrm{M}$ (Fig. 3A). This greater activity upon increased salt concentration is consistent with the activity observed in halophilic proteins $(18,57)$. The optimal activity at $0.5 \mathrm{M} \mathrm{NaCl}$ also supports our proposition that the lowest hydroxyl group interaction at $0.5 \mathrm{M} \mathrm{NaCl}$ might reflect a more defined and functional structure. Nonetheless, this structure must still have dynamic fluctuations at $0.5 \mathrm{M}$ to meet the required conformational changes during catalysis. In fact, the hydroxyl group interaction of BR3 Pol at $0.5 \mathrm{M}$ was even higher than that of KOD Pol (Fig. 2C).

Pfu Pol and KOD Pol were more active than BR3 Pol at lower salt concentrations, but their activity declined dramatically beyond 20 and $100 \mathrm{mM} \mathrm{NaCl}$, respectively (Fig. 3B, C). BR3 Pol also displayed remarkable resistance to increasing concentrations of a variety of salts (Supplemental Fig. 3B). The trend in polymerase activity in 
A

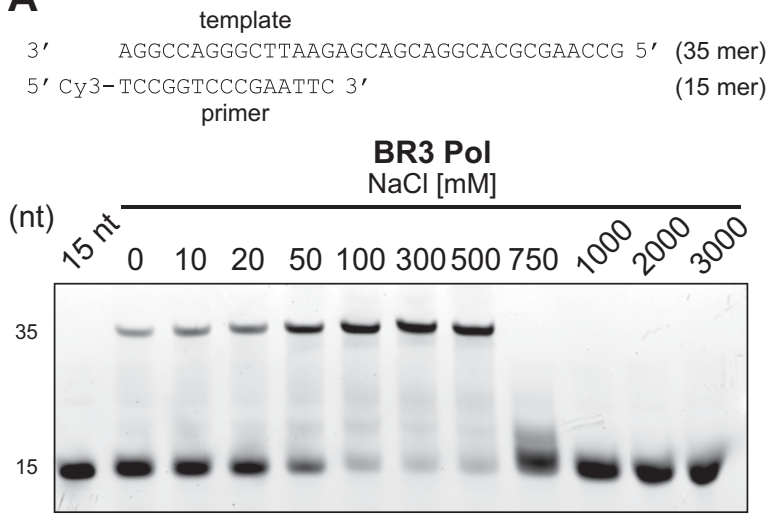

B

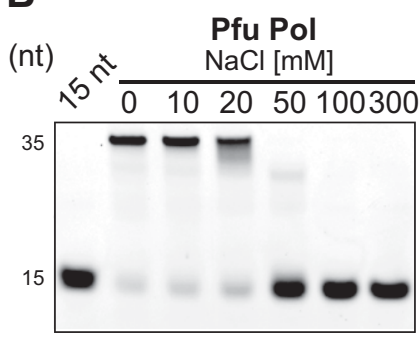

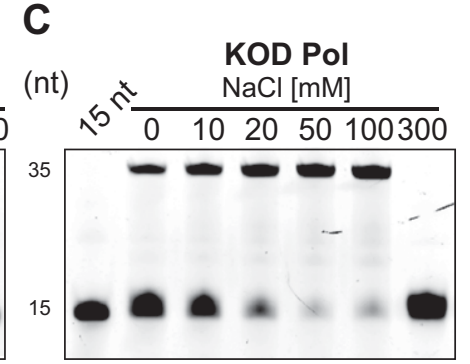
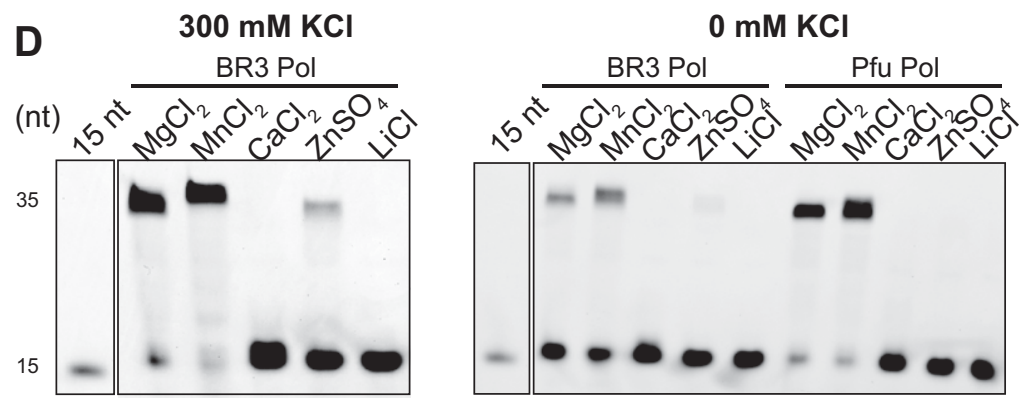

E

$300 \mathrm{mM} \mathrm{KCl}$

BR3 Pol

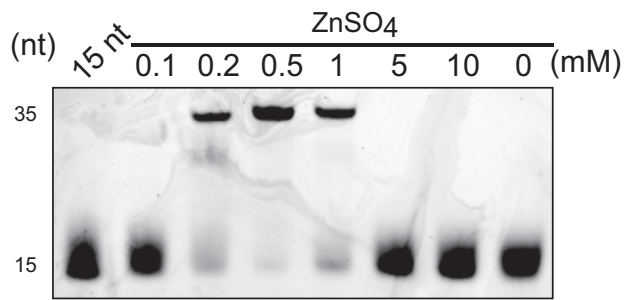

Figure 3. Dependence of the polymerase activity on salt and metal ions. A) Salt-dependent polymerization activity of BR3 Pol. Polymerase activity was measured on a short primer/template substrate consisting of a 15 -mer primer labeled at its $5^{\prime}$ end with Cy3 and a 35-mer template strand (insert schematic). Reactions were performed in a buffer containing the indicated concentration of $\mathrm{NaCl}$ for $4 \mathrm{~min}$ at $45^{\circ} \mathrm{C}$ and stopped by EDTA, as described in the Materials and Methods section. Products were analyzed on a denaturing $20 \%$ polyacrylamide urea gel. $B, C$ ) Salt-dependent polymerization activity of Pfu Pol and KOD Pol, respectively. $D$ ) Effect of different metal ions on the polymerization activity of BR3 Pol compared with Pfu Pol. Different metal ions were added at a constant concentration of $2 \mathrm{mM}$ with the reaction performed in a buffer containing either $300 \mathrm{mM} \mathrm{KCl}$ (left panel) or $0 \mathrm{mM} \mathrm{KCl}$ (right panel). E) Effect of increasing $\mathrm{ZnSO}_{4}$ concentration on the polymerization activities of BR3 Pol in a reaction buffer containing $300 \mathrm{mM} \mathrm{KCl}$. Reactions in $B-E$ were performed and analyzed as in $A$.

different salt concentrations among these polymerases reflects the trend in the external salt concentrations of their harboring archaea species $(58,59)$, suggesting that the macromolecules of archaea from the deep-sea brines in the Red Sea, as well as their membrane transport mechanisms, adapt to the intracellular salt concentration $(18,60)$.

We also measured the rate and processivity of BR3 Pol by a well-established single molecule replication assay that monitors DNA synthesis by measuring the change in the length of flow-stretched individual DNA molecules (33). Briefly, a $\sim 7 \mathrm{kbp}$ ssDNA template was attached from 1 end to the surface of a glass coverslip of a microfluidic flow cell and from the other end to a magnetic bead (Fig. 4A) and extended by a laminar flow exerting a $\sim 3 \mathrm{pN}$ drag force on the beads. Primer extension converts the template strand from ssDNA (short) to dsDNA (long), causing an overall lengthening of the surface-tethered DNA molecules. The single molecule replication trajectories, at optimal $250 \mathrm{mM} \mathrm{KCl}$, showed that the DNA synthesis segment was interrupted by pauses with no DNA synthesis (Fig. $4 B$ ). These pauses likely represent dissociation and reassociation events of the polymerases from solution because the polymerases are continuously present in the solution. The DNA synthesis phase would therefore represent the intrinsic rate and processivity of the DNA polymerase. By averaging over multiple segments $(n)$ of the DNA synthesis phase $(n=83)$, the rate and processivity of BR3 Pol were found to be $460 \pm 35$ base/s and $2.00 \pm 0.03 \mathrm{~kb}$, respectively. In comparison, the rate and processivity of Pfu Pol, at optimal $0 \mathrm{mM} \mathrm{KCl}$, were $305 \pm 40$ base/s ( $n=$ 73) and $1.30 \pm 0.10 \mathrm{~kb}$ (Fig. 4C,D). These data show that BR3 Pol is 1.5-fold more active than Pfu Pol. The rate of $\mathrm{Pfu}$ Pol is significantly higher than previously reported in the literature using bulk replication assays (61). This outcome is likely due to including the pause duration in bulk replication assays, which would result in reporting slower apparent rates (Supplemental Fig. 7A, B). Bulk exonuclease proofreading assays, as described in the Materials and Methods section, showed that BR3 Pol had $\sim 2$-fold higher proofreading activities than Pfu Pol did at their corresponding optimal salt concentrations (Supplemental Fig. $8 A-D$ ).

\section{BR3 Pol can effectively use $\mathrm{Zn}^{2+}$ ions as cofactors}

The brine pools contain high concentrations of a variety of metal ions, including heavy metals (1). At an optimal high salt concentration $(300 \mathrm{mM} \mathrm{KCl})$ and a fixed concentration of metal ions (2 mM), BR3 Pol mediated extensive DNA synthesis using $\mathrm{Mg}^{2+}$, the most desired metal ion by DNA polymerases, as well as $\mathrm{Mn}^{2+}$, a popular alternative metal 
A

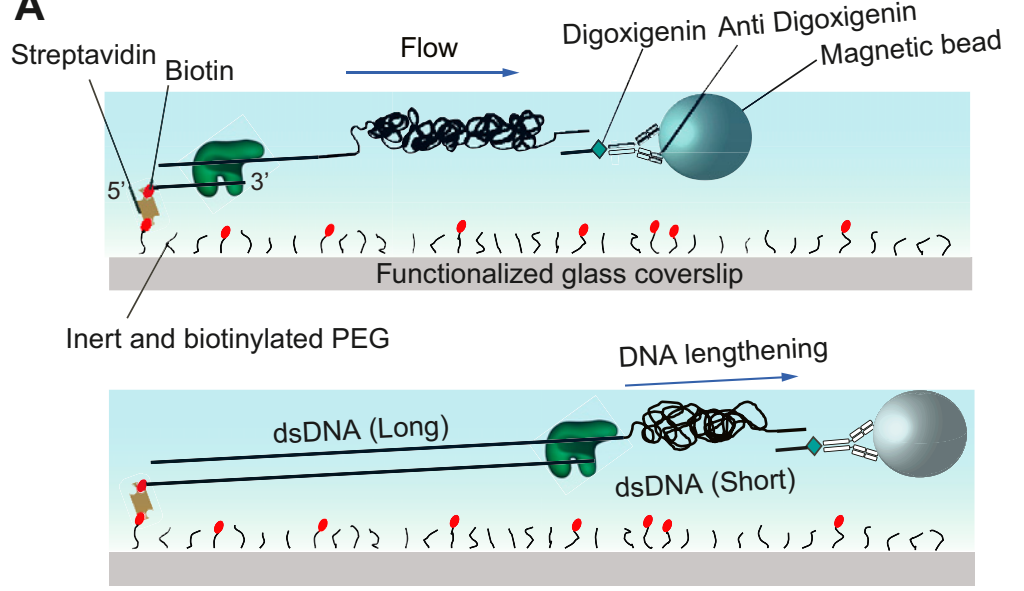

B

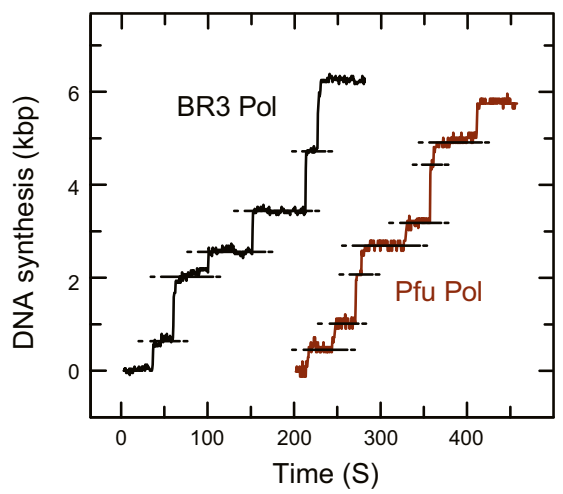

C

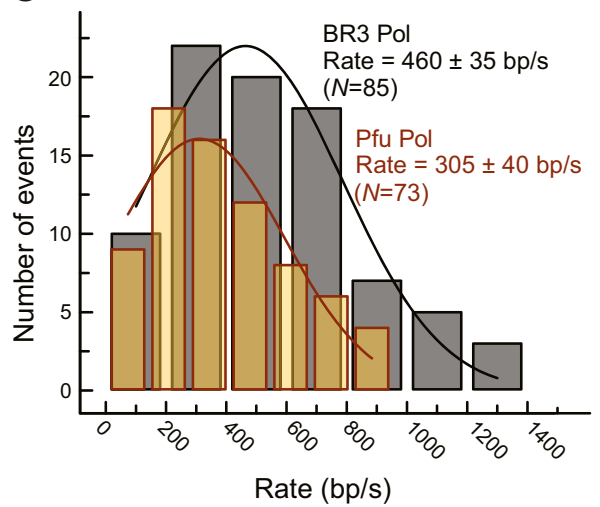

D

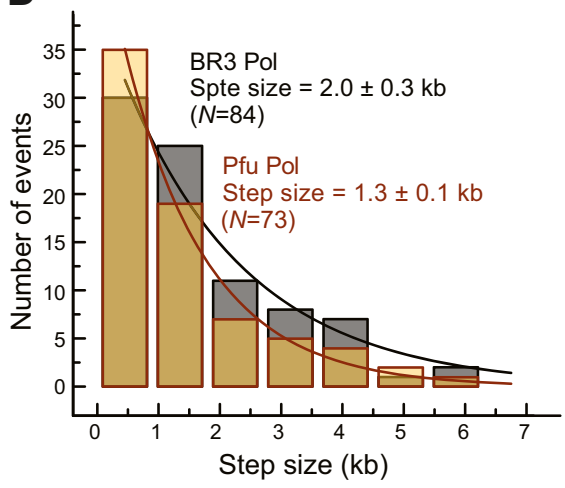

Figure 4. Single-molecule measurements of rate and processivity of BR3 Pol and Pfu Pol. A) Schematic depiction of the singlemolecule assay for observing the primer extension reaction. B) Representative primer extension trajectories by BR3 Pol and Pfu Pol. Dotted lines indicate pausing of the primer extension, which represents points where a minimum of $3 \mathrm{~s}$ of no change in DNA length was detected. $C$ ) Distribution of rate of DNA synthesis by BR3 Pol and Pfu Pol extracted from the slope of the DNA lengthening phase in $B$ fitted with a gaussian distribution. $D$ ) Distribution of processivity of DNA synthesis by BR3 Pol and Pfu Pol, extracted from the magnitude of the DNA lengthening phase in $B$ fitted with a single exponential decay. Reactions were performed in a buffer containing $250 \mathrm{mM} \mathrm{KCl}$ for BR3 Pol and $0 \mathrm{mM} \mathrm{KCl}$ for Pfu Pol. The uncertainty corresponds to the SD of the fit.

ion (62) (Fig. 3D). Surprisingly, we also detected weaker activity of BR3 Pol in the presence of $\mathrm{Zn}^{2+}$ ions but not in the presence of $\mathrm{Li}^{+}$ions. Similar results were observed at the suboptimal salt concentration $(0 \mathrm{mM} \mathrm{KCl})$. In a control experiment, we showed that Pfu Pol was also most active in the presence of $\mathrm{Mg}^{2+}$ and $\mathrm{Mn}^{2+}$, although, in contrast to BR3 Pol, it was completely inactive in the presence of $\mathrm{Zn}^{2+}$ ions. Varying the concentration of $\mathrm{Zn}^{2+}$ ions showed that BR3 Pol activity could be dramatically increased at concentrations below $1 \mathrm{mM}$ (Fig. $3 E$ ), approaching the activity measured in the presence of $\mathrm{Mg}^{2+}$ and $\mathrm{Mn}^{2+}$. These results suggest that BR3 Pol can effectively align the primer/ template strands and the incoming dNTP via $\mathrm{Zn}^{2+}$ ions in its active site in contrast to other DNA polymerases. In the absence of salt, BR3 pol could use $\mathrm{Mg}^{2+}$ or $\mathrm{Mn}^{2+}$ as alternative sources of salt and could tolerate these metal ions at higher concentrations than could KOD Pol and Pfu Pol (Supplemental Fig. 3C, D). Collectively, these results show that BR3 Pol exhibits an outstanding tolerance to elevated $\mathrm{MgCl}_{2}$ and $\mathrm{MnCl}_{2}$ and an unusual ability to effectively utilize $\mathrm{Zn}^{2+}$ ions.

\section{Engineering a halophilic version of KOD Pol}

We next investigated which regions in BR3 Pol are responsible for its salt tolerance. Due to the absence of a BR3 Pol structure, we relied on the strategy of replacing regions in KOD Pol with their corresponding homologous regions in BR3 Pol. Chimera proteins were constructed by swapping the exonuclease, fingers, and thumb domains of BR3 Pol with those in KOD Pol as illustrated in Fig. 5A. We found that $\mathrm{KOD}_{\mathrm{BR} 3 \text { exo }}$ and $\mathrm{KOD}_{\mathrm{BR} 3 \text { thumb }}$ exhibited increased salt tolerance of up to 3-fold higher than that of KOD Pol WT (Fig. 5B-D). KOD BR3fingers $_{\text {also exhibited }}$ greater salt tolerance than KOD Pol WT, but this tolerance was smaller than that of $\mathrm{KOD}_{\mathrm{BR} 3 \text { exo }}$ and $\mathrm{KOD}_{\mathrm{BR} 3 \text { thumb }}$ (Fig. $5 E$ ). These results suggest that the exonuclease and thumb domains and, to a lesser extent, the fingers domains of BR3 Pol contribute to the ability of BR3 Pol to endure under high salt conditions. The inability of any of the chimera KOD proteins to approach the salt tolerance ability of $\mathrm{BR} 3 \mathrm{Pol}$ ( $\sim 500 \mathrm{mM} \mathrm{NaCl})$ indicates that all these domains collectively contribute to the salt tolerance mechanism of BR3 
A

BR3 and KOD proteins

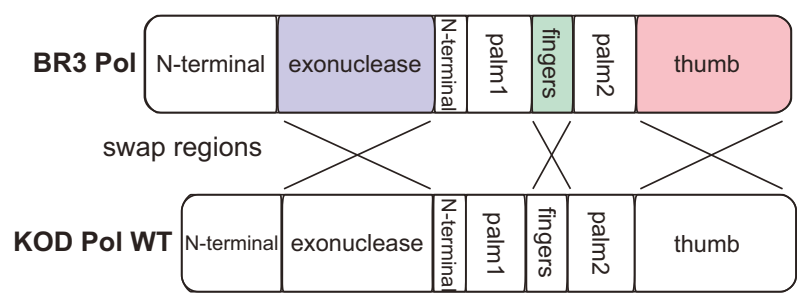

\section{Chimera proteins with regions swapped between BR3 and KOD}

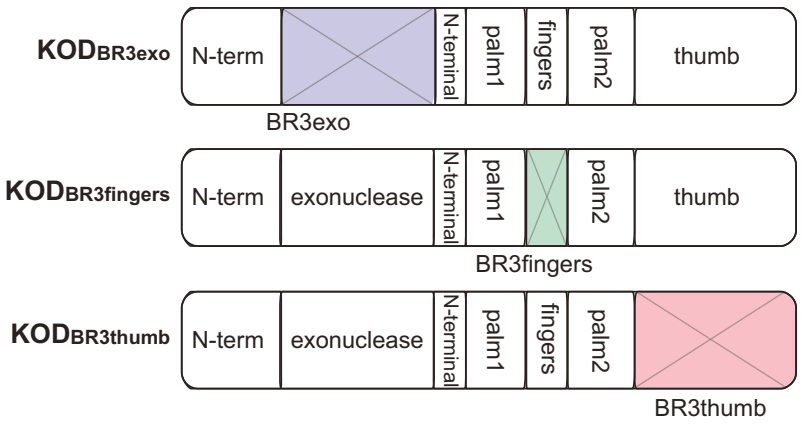

B

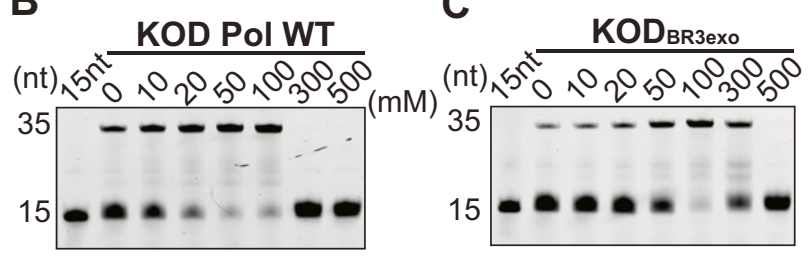

D
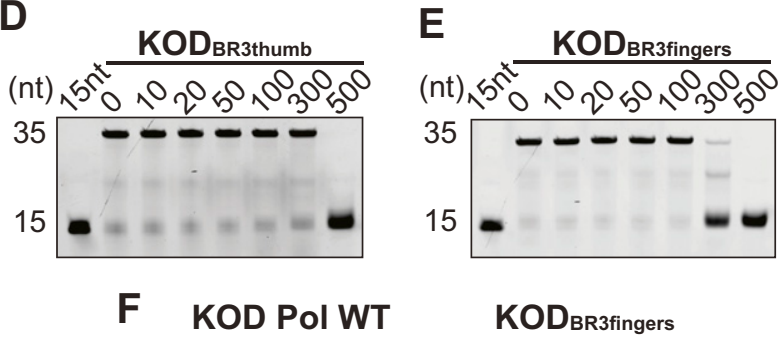

KODBR3fingers

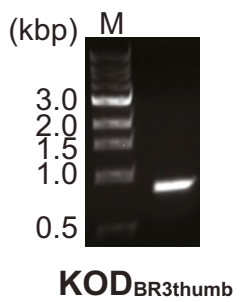

$(\mathrm{kbp})$

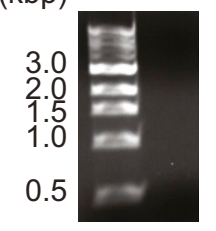

(kbp)

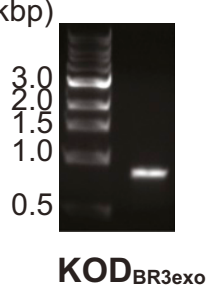

(kbp)

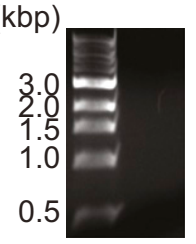

Figure 5. Salt-dependent polymerization activity of KOD Pol and its chimera proteins. A) Schematic of KOD Pol WT and chimeric proteins constructed between KOD Pol and BR3 Pol. The exonuclease, fingers, and thumb domains of KOD Pol swapped with those from BR3 Pol are shown in purple, green, and red, respectively. $B-E$ ) are the polymerization activities at increasing NaCl concentrations for KOD Pol WT, KOD ${ }_{\mathrm{BR} 3 \mathrm{exo}}, \mathrm{KOD}_{\mathrm{BR} 3 \text { thumb, }}$ and $\mathrm{KOD}_{\mathrm{BR} 3 f i n g e r s}$. The reaction was conducted and the product was analyzed as described in Fig. 3A. F) PCR test of KOD chimera proteins. PCR reactions were performed as described in the Materials and Methods section by KOD Pol WT, KOD BR3fingers, $_{\text {KOD }}$ BR3thumb, and KOD $\mathrm{BR}_{\text {Bexo. }}$.

Pol. The fact that the intrinsic polymerization activity was intact in the KOD Pol chimera proteins indicates that the introduced charged residues in the chimera KOD proteins might be responsible for their increased salt tolerance ability. Interestingly, the number of unique acidic residues introduced to KOD Pol by swapping the domains from BR3 Pol $\left(18,15\right.$, and 4 for $\mathrm{KOD}_{\text {BR3exo, }} \mathrm{KOD}_{\mathrm{BR} 3 \text { thumb, }}$ and $\mathrm{KOD}_{\text {BR3fingers, }}$ respectively) correlates with the enhanced salt tolerance in the chimera proteins. These results also show that domain swapping to convert nonhalophilic to halophilic polymerase would be an effective engineering strategy among these homologous DNA polymerases.

Testing the activity of these chimera proteins at higher temperatures by PCR amplification yielded important results. Only $\mathrm{KOD}_{\mathrm{BR} 3 \mathrm{fingers}}$ maintained its activity at higher temperatures, whereas such activity was completely lost in $\mathrm{KOD}_{\mathrm{BR} 3 \text { exo }}$ and $\mathrm{KOD}_{\mathrm{BR} 3 \text { thumb }}$ (Fig. 5F). These results further support our hypothesis that disulfide bonds in the palm domain are not the primary contributor to thermal stability. They also showed that improving salt tolerance in $\mathrm{KOD}_{\mathrm{BR} \text { зехо }}$ and $\mathrm{KOD}_{\mathrm{BR} 3 \text { thumb }}$ suppressed their activity at high temperatures. We suspect that this action is caused by the enhanced structural flexibility of the chimera proteins upon introducing the exonuclease or the thumb domains of BR3 Pol.

\section{BR3 Pol maintains DNA binding at elevated salt concentrations}

To understand the influence of salt concentration on the DNA-binding affinity and specificity of BR3 Pol, we first characterized the nonspecific interactions of BR3 Pol with ssDNA and dsDNA and the specific interactions with primer/template strands in a side-by-side comparison with KOD Pol, using SPR (Fig. 6A). At $100 \mathrm{mM} \mathrm{NaCl}$, BR3 Pol bound the primer/template strands with a 4.5-fold higher equilibrium dissociation binding constant $\left(K_{d}\right)$ than did KOD Pol (Fig. 6B, C and Table 1). Both BR3 Pol and KOD Pol discriminated against binding to dsDNA and to a lesser extent against ssDNA. At $300 \mathrm{mM} \mathrm{NaCl}, \mathrm{BR} 3 \mathrm{Pol}$ bound the primer/template strands 3-fold more strongly than that at $100 \mathrm{mM}$ and also increased its discrimination 
A

primer/template ssDNA dsDNA

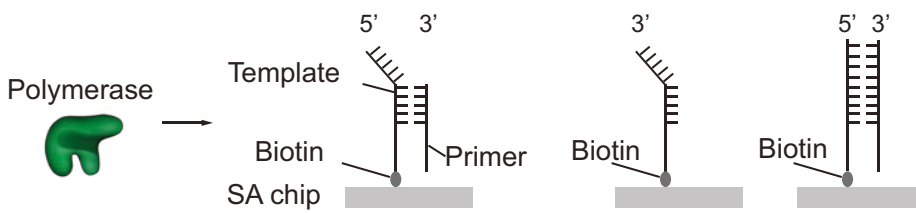

B
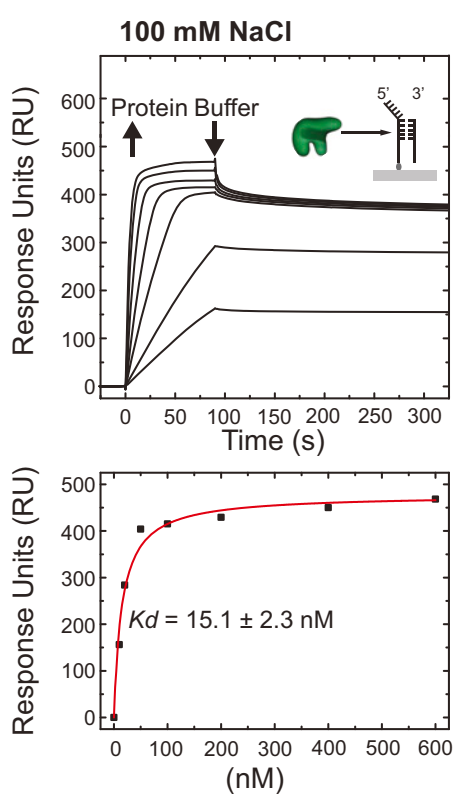

E
C
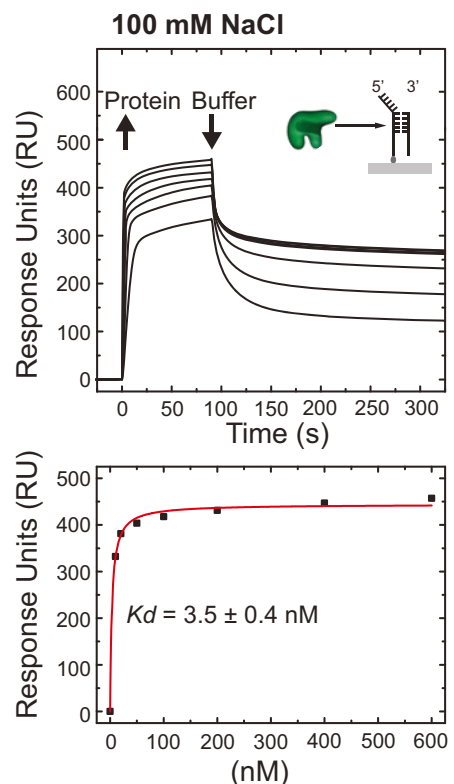

D BR3 Pol
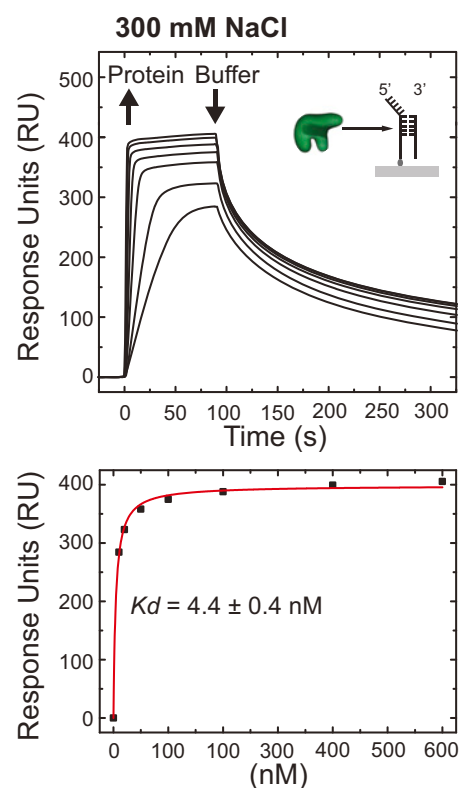

\section{$100 \mathrm{mM} \mathrm{NaCl}$}

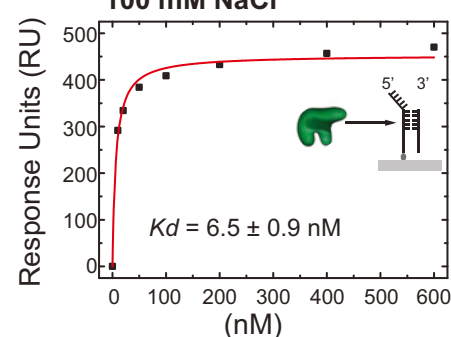

(nM)

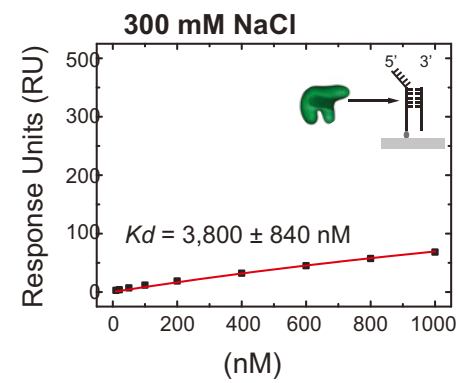

F

KODBR3thumb $100 \mathrm{mM} \mathrm{NaCl}$
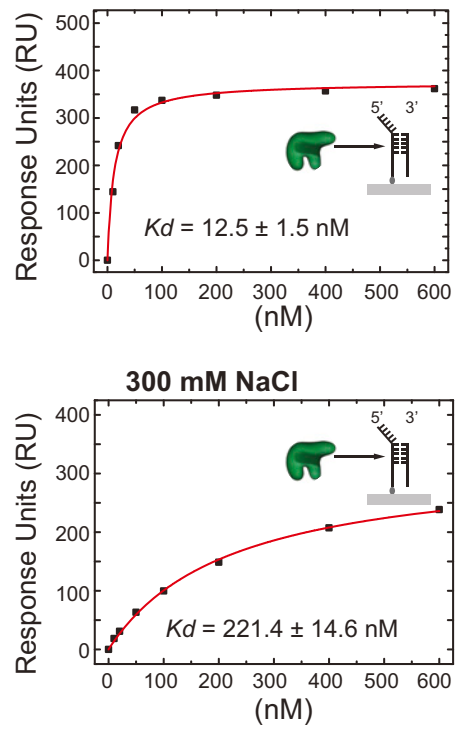

Figure 6. Interactions of BR3 Pol, KOD Pol WT, and KOD chimera proteins with DNA by SPR. A) Schematic of the experiment showing the 3 different biotinylated DNA constructs that were immobilized on 3 independent flow cells on a streptavidin (SA)sensor chip and the injection of the polymerase in solution; a fourth flow cell with no DNA was used to subtract nonspecific interactions between the protein and the surface and the buffer's refractive index. The 3 tested DNA constructs are primer/ template strands (left panel), ssDNA (middle panel), and dsDNA (right panel). B) Binding of BR3 Pol to primer/template strands in a buffer containing $100 \mathrm{mM} \mathrm{NaCl}$. Upper panel: serial concentrations of BR3 Pol were injected (10, 20, 50, 100, 200, 400 , and $600 \mathrm{nM}$ concentrations) with a surface-regeneration step to remove the bound protein in between. Lower panel: the maximum RUs reached at each protein concentration were fitted using the steady-state affinity mode to obtain the equilibrium dissociation constant $\left(K_{d}\right)$ for each DNA substrate. The uncertainty corresponds to the SD of the fit. $C$ ) Binding of KOD Pol to primer/template strands in a buffer containing $100 \mathrm{mM} \mathrm{NaCl}$. Experiments were performed and analyzed as in $B$ and the protein 
against ssDNA to reach that of dsDNA (Fig. $6 B, D$ ). The faster reduction in RUs of the bound polymerase during the buffer washing step at $300 \mathrm{mM}$ compared with $100 \mathrm{mM}$ suggests that the dissociation rate constant is faster at $300 \mathrm{mM}$. Therefore, the decrease in $K_{d}$ at $300 \mathrm{mM}$ is likely due to a significant increase in the association rate constant. The increased specificity to the primer/template structure over ssDNA and dsDNA at higher salt concentrations support our proposition that the decrease in the hydroxyl group interaction from 0 to $0.5 \mathrm{M} \mathrm{NaCl}$ might reflect a transition from a dynamic to a more defined and functional structure. KOD Pol WT, conversely, failed to bind the primer/template strands at $300 \mathrm{mM}$, indicating why it showed no activity at these elevated salt concentrations.

The 3-fold increase in salt tolerance in $\mathrm{KOD}_{\mathrm{BR} 3 \text { exo }}$ and $\mathrm{KOD}_{\mathrm{BR} 3 \text { thumb }}$ chimera proteins prompted us to hypothesize that the inserted BR3 exonuclease and thumb domains improved the DNA-binding affinity of KOD Pol. At $100 \mathrm{mM} \mathrm{NaCl}, \mathrm{KOD}_{\text {BR3exo }}$ and $\mathrm{KOD}_{\text {BR3thumb }}$ bound the primer/template strands but with 2- and 4-fold increased $K_{d}$ compared with KOD Pol WT (Fig. 6E, F and Table 1). At $300 \mathrm{mM} \mathrm{NaCl}$, however, $\mathrm{KOD}_{\text {BR3 thumb }}$ retained binding to the primer/template strands in contrast to no binding by KOD Pol WT. We also observed residual binding of $\mathrm{KOD}_{\text {BR3exo }}$ at $300 \mathrm{mM} \mathrm{NaCl}$. The weaker intrinsic DNAbinding affinity of $\mathrm{KOD}_{\mathrm{BR} 3 \text { thumb }}$ and $\mathrm{KOD}_{\mathrm{BR} 3 \text { exo }}$ at $100 \mathrm{mM}$ suggests that the ability to bind DNA at $300 \mathrm{mM}$ $\mathrm{NaCl}$ might result from improved structural adaptation to maintain functional conformation at higher salt concentrations. Collectively, these results indicate that the mechanism of salt tolerance by BR3 Pol could be assisted by its high affinity to the primer/template strands and its ability to retain functional conformation.

\section{DISCUSSION}

Enzyme stability requires structural rigidity, whereas its function requires flexibility to meet required conformational changes during catalysis. It is proposed that enzymes from extreme thermophiles may form rigid structures and rely on temperature variation to balance rigidity with flexibility, whereas enzymes from halophiles may require flexible structures to counteract salt-induced rigid hydrophobic packing. Halophilic proteins would therefore need to balance the structural requirements between being flexible and yet rigid enough to avoid unfolding.

Several mechanisms have been proposed to explain the adaptation of halophilic proteins to hypersaline conditions. Although it is difficult to generalize these mechanisms, it remains widely accepted that increasing the negatively charged residues on the protein's surface is a common adaptive mechanism $(13,15,18,19,41)$. Comparison of BR3 Pol with mesophilic yPolD showed an increase in both negatively and positively charged residues of BR3 Pol, with the number of negative residues being significantly higher (Fig. $1 B, C$ and Supplemental Fig. $2 B, C$ ). How excess negative charges affect the structural adaptation mechanisms of halophilic proteins is a topic of continued investigation.

Accurate predictions of intrinsic disorder in halophilic archaea species indicate that their proteins are generally rich in disordered regions (63). We predicted the intrinsic disorder of BR3 Pol using RONN and noticed that this polymerase contains significantly more disordered regions than does the mesophilic yPolD (Fig. 2B and Supplemental Fig. 6A). Secondary structural analysis according to Raman spectroscopy further supported the conclusion that BR3 Pol has more disordered regions than KOD Pol and that these disordered regions mainly consist of random coils (Fig. 2A). We used the structure of KOD Pol to make a structural prediction on the location of the disordered regions and negative charges in BR3 Pol. In all, 63 and $36 \%$ of the unique Asp and Glu residues, respectively, mapped primarily to the random coils of BR3 Pol (Supplemental Fig. 6C). The proposition that Asp increases random coils as an $\alpha$-helix breaker $(51,52)$ indicates a correlation between the unique Asp residues and the random coils in BR3 Pol.

Secondary structure analysis and hydroxyl group interaction as observed by using Raman spectroscopy (Fig. 2A, C) combined with activity and DNA-binding assays (Figs. $3 A$ and $6 B, D$ and Table 1 ) at different salt concentrations confirmed that BR3 Pol is structurally flexible. These tests also unraveled how this flexibility mediates the polymerase's adaptation to hypersaline conditions. Interestingly, salt has a minimal effect on the overall secondary structure of BR3 Pol (Fig. $2 A$ and Supplemental Fig. $6 B)$, suggesting that the observed higher activity and the specificity of DNA binding upon increasing salt concentration reflects transitioning to a functional structure that is primarily driven by dynamic fluctuations in the protein rather than by disorder-to-order structural transitioning. We propose that repulsive forces among closely located negative charges, in addition to the high percentage of random coils that are negatively charged, provide structural flexibility and dynamism even at elevated salt concentrations (Fig. 7). Repulsive forces might also act among different protein molecules to prevent aggregation. This salt-induced structural transitioning might be a universal mechanism that could explain the general trend of salt-induced activation in halophilic proteins $(18,57,64)$.

The possibility for extremely thermophilic proteins to adapt lies in the stability of their structures from strong hydrophobic packing, salt bridge interactions, and disulfide bonds $(15,22,23,45,65)$. Although the overall composition of hydrophobic residues with large or small side chains in KOD Pol and Pfu Pol was not significantly

concentrations used were 10, 20, 50, 100, 200, 400, and $600 \mathrm{nM} . D$ ) Binding of BR3 Pol to primer/template strands in a buffer containing $300 \mathrm{mM} \mathrm{NaCl}$. Experiments were performed and analyzed as in $B$, and the protein concentrations used were 10 , 20 , $50,100,200,400$, and $600 \mathrm{nM} . E, F) K_{d}$ of $\mathrm{KOD}_{\mathrm{BR} 3 \text { exo }}$ and $\mathrm{KOD}_{\mathrm{BR} 3 \text { thumb }}$ to primer/template strands in a buffer containing 100 or $300 \mathrm{mM} \mathrm{NaCl}$, respectively. $K_{d}$ was calculated as described in $B$. 


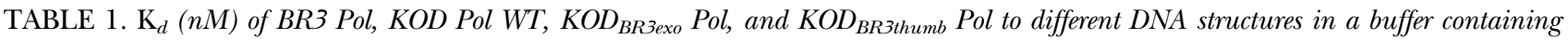
$100 \mathrm{mM} \mathrm{NaCl}$ or $300 \mathrm{mM} \mathrm{NaCl}$

\begin{tabular}{|c|c|c|c|c|c|c|c|c|}
\hline Heading & $100 \mathrm{mM}$ & $300 \mathrm{mM}$ & $100 \mathrm{mM}$ & $300 \mathrm{mM}$ & $100 \mathrm{mM}$ & $300 \mathrm{mM}$ & $100 \mathrm{mM}$ & $300 \mathrm{mM}$ \\
\hline dsDNA & 251.0 & 178.1 & 238.6 & NA & & & & \\
\hline Primer/template $(\mathrm{nm})$ & 15.1 & 4.4 & 3.5 & NA & 6.5 & 3800 & 12.5 & 221.4 \\
\hline
\end{tabular}

different from that of mesophilic yPolD and even similar to that of BR3 Pol (Supplemental Fig. 2A), we found that there was an increase in the percentage of negative and positive charges in KOD Pol, Pfu Pol, and BR3 Pol (Fig. 1B). Structural prediction analysis showed that KOD Pol and Pfu Pol exhibited significant reductions in their structural flexibility (Fig. $2 B$ and Supplemental Fig. 6A), suggesting that they maintained rigid and stable structures. Raman structural analysis on KOD Pol supported these findings by showing significantly fewer random coils (Fig. 2A). Although disulfide bonds in the palm domain of extremely thermophilic DNA polymerases have been proposed to play a key role in their thermal stability (38), our findings allowed us to conjecture that this theory is not the case (Supplemental Fig. 3A). Our results indicate that polymerases from extreme thermophiles adapt to high temperatures by primarily relying on salt bridge interactions and less flexible structures. Although BR3 Pol is a thermophilic polymerase, it displayed significant structural flexibility compared with KOD Pol. We posit that the primary adaptation mechanism for its thermal stability may be from stabilizing its structure through salt bridge interactions. The balance between structural rigidity for thermal adaptation and flexibility for salt adaptation would be achieved by the relative abundance of salt bridge interactions vs. excess negative charges.

Although it has been reported that some DNA polymerases exhibit residual activity in the presence of $\mathrm{Zn}^{2+}$ ions (66), BR3 Pol is exceptional in that it can achieve a similar activity level with $\mathrm{Zn}^{2+}$ ions as with $\mathrm{Mg}^{2+}$ ions but at a significantly lower concentration of $\mathrm{Zn}^{2+}$ ions (Fig. 3E). Amino acid comparisons showed that the active site contains highly conserved acidic residues that coordinate the metal ions (Supplemental Fig. 1). It is difficult, however, to understand the mechanistic bases of BR3 Pol's ability to use $\mathrm{Zn}^{2+}$ without its crystal structure in complex with DNA. We believe that the higher flexibility of the palm and fingers domains in BR3 Pol might enable it to adapt its
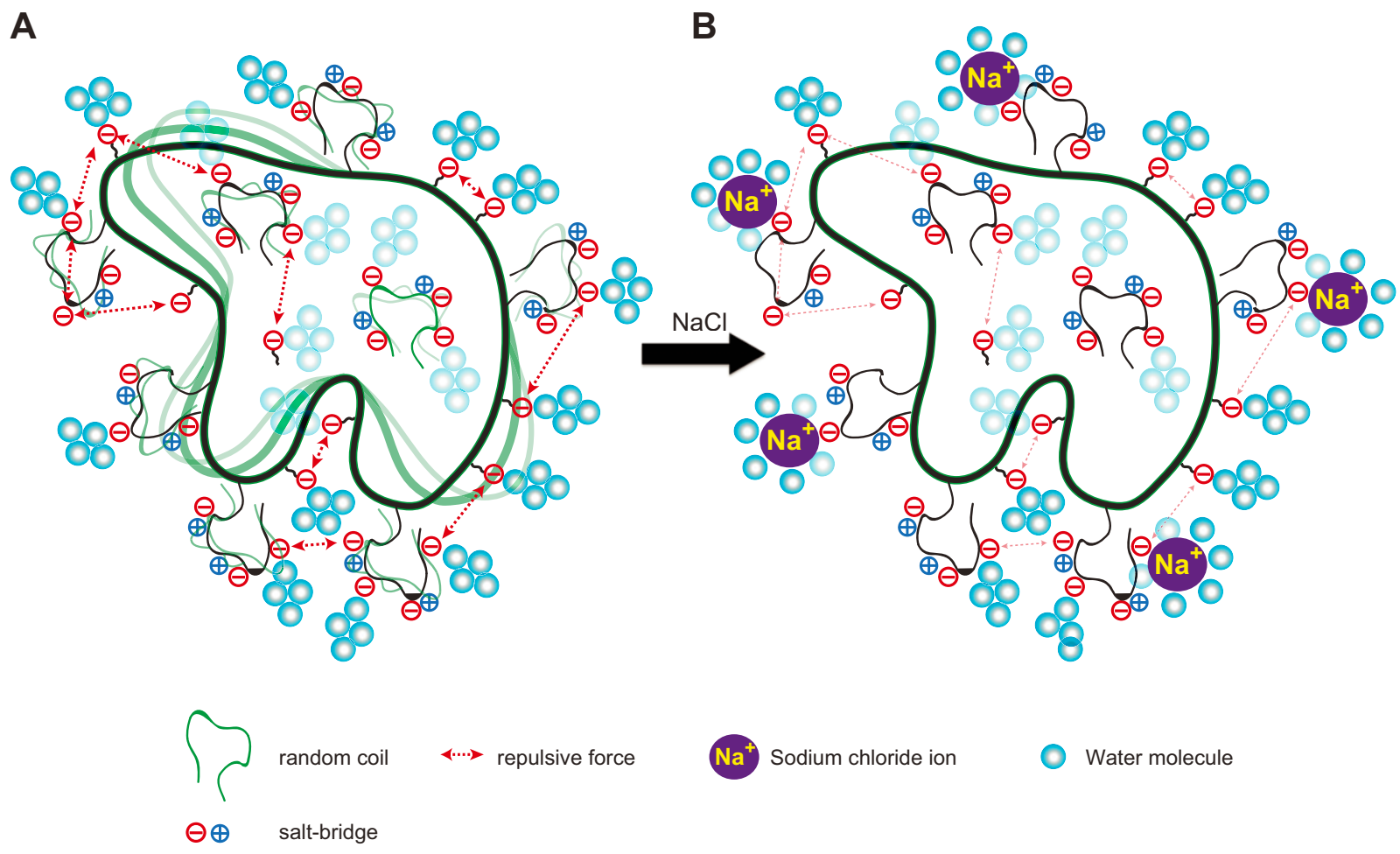

Sodium chloride ion

Water molecule

Figure 7. Negatively charged random coils mediate salt-induced transitioning from a flexible to a defined structure. $A$ ) In the absence of salt, the polymerase experiences dynamic structural fluctuations as a result of its increased percentage of random coils. Excess negative charges (Asp and Glu) on the surface and/or on the random coils mediate this flexibility through repulsive forces. $B$ ) In the presence of salt, the binding of hydrated $\mathrm{Na}^{+}$ions to acidic residues stabilizes the random coils and reduces the dynamic structural fluctuations leading to the formation of a more functional conformer. 
conformations in the active site, allowing it to effectively align the incoming nucleotide and the primer/template strands in the presence of $\mathrm{Zn}^{2+}$ relative to other DNA polymerases.

The increase in negative charges in halophilic proteins raises a paradoxical puzzle about how halophilic DNA-binding proteins interact with DNA at elevated salt concentrations. Previous studies on the halophilic TBP transcription factor suggest that incorporation of negatively charged residues into the DNA-binding region would sequester cations, allowing the protein to interact indirectly with the DNA phosphate backbone via salt bridges $(24,25)$. This mechanism is appealing because negative charges would also contribute to the adaptation of the protein's structure to hypersaline conditions. Here, we described an alternative DNA-binding mechanism in which BR3 Pol used the conventional direct DNA-binding mode through a positively charged crevice (Supplemental Fig. 1), which is structurally adapted to maintain functional conformers at elevated salt concentrations.

\section{ACKNOWLEDGMENTS}

The authors thank the King Abdullah University of Science and Technology (KAUST) BioScience Core Laboratory for providing Pfu polymerase. This research was funded by the Saudi Economic and Development Company (SEDCO) Research Excellence Project and baseline funding from KAUST to S.M.H. The authors declare no conflicts of interest.

\section{AUTHOR CONTRIBUTIONS}

This study was initiated, designed, and supervised by M. Takahashi, U. Stingl, J. S. Merzaban, E. Di Fabrizio, and S. M. Hamdan; M. Takahashi, E. Takahashi, and K. Sakashita performed molecular cloning, protein purifications, and bulk assays; M. Takahashi and M. Tehseen performed protein purifications; L. I. Joudeh designed and performed the SPR assays; M. Takahashi and M. M. Elshenawy designed and performed the single-molecule replication assays; M. A. Sobhy established the single-molecule flow stretching setup; K. Sakashita and I. Alam performed the BLAST search; M. Marini, G. Das, and E. Di Fabrizio designed, performed, and analyzed the Raman experiments; M. Marini and A. Akal performed and analyzed the CD experiments; M. Takahashi and S. M. Hamdan wrote the manuscript, and all authors read and commented on the manuscript.

\section{REFERENCES}

1. Antunes, A., Ngugi, D. K., and Stingl, U. (2011) Microbiology of the Red Sea (and other) deep-sea anoxic brine lakes. Environ. Microbiol. Rep. 3, 416-433

2. Hartmann, M., Scholten, J. C., Stoffers, P., and Wehner, F. (1998) Hydrographic structure of brine-filled deeps in the Red Sea-new results from the Shaban, Kebrit, Atlantis II, and Discovery Deep. Mar. Geol. 144, 311-330

3. Bäcker, H., and Schoell, M. (1972) New deeps with brines and metalliferous sediments in the Red Sea. Nat. Phys. Sci. 240, 153-158

4. Amann, R. I., Ludwig, W., and Schleifer, K. H. (1995) Phylogenetic identification and in situ detection of individual microbial cells without cultivation. Microbiol. Rev. 59, 143-169
5. Antunes, A., Alam, I., Bajic, V. B., and Stingl, U. (2011) Genome sequence of Halorhabdus tiamatea, the first archaeon isolated from a deep-sea anoxic brine lake. J. Bacteriol. 193, 4553-4554

6. Alam, I., Antunes, A., Kamau, A. A., Ba Alawi, W., Kalkatawi, M., Stingl, U., and Bajic, V. B. (2013) INDIGO-INtegrated data warehouse of microbial genomes with examples from the Red Sea extremophiles. PLoS One 8, e82210

7. Yooseph, S., Sutton, G., Rusch, D. B., Halpern, A. L., Williamson, S. J. Remington, K., Eisen, J. A., Heidelberg, K. B., Manning, G., Li, W., Jaroszewski, L., Cieplak, P., Miller, C. S., Li, H., Mashiyama, S. T., Joachimiak, M. P., van Belle, C., Chandonia, J. M., Soergel, D. A., Zhai, Y., Natarajan, K., Lee, S., Raphael, B. J., Bafna, V., Friedman, R., Brenner, S. E., Godzik, A., Eisenberg, D., Dixon, J. E., Taylor, S. S., Strausberg, R. L., Frazier, M., and Venter, J. C. (2007) The Sorcerer II Global Ocean Sampling expedition: expanding the universe of protein families. PLoS Biol. 5, e16

8. Arakawa, T., and Timasheff, S. N. (1982) Preferential interactions of proteins with salts in concentrated solutions. Biochemistry 21, $6545-6552$

9. Ruckenstein, E., and Shulgin, I. L. (2006) Effect of salts and organic additives on the solubility of proteins in aqueous solutions. Adv. Colloid Interface Sci. 123-126, 97-103

10. Karan, R., Capes, M. D., and Dassarma, S. (2012) Function and biotechnology of extremophilic enzymes in low water activity. Aquat. Biosyst. 8, 4

11. Arakawa, T., and Timasheff, S. N. (1984) Mechanism of protein salting in and salting out by divalent cation salts: balance between hydration and salt binding. Biochemistry 23, 5912-5923

12. Frolow, F., Harel, M., Sussman, J. L., Mevarech, M., and Shoham, M. (1996) Insights into protein adaptation to a saturated salt environment from the crystal structure of a halophilic 2Fe-2S ferredoxin. Nat. Struct. Biol. 3, 452-458

13. Tadeo, X., López-Méndez, B., Trigueros, T., Laín, A., Castaño, D., and Millet, O. (2009) Structural basis for the aminoacid composition of proteins from halophilic archea. PLoS Biol. 7, e1000257

14. Kastritis, P. L., Papandreou, N. C., and Hamodrakas, S. J. (2007) Haloadaptation: insights from comparative modeling studies of halophilic archaeal DHFRs. Int. J. Biol. Macromol. 41, 447-453

15. Reed, C. J., Lewis, H., Trejo, E., Winston, V., and Evilia, C. (2013) Protein adaptations in archaeal extremophiles. Archaea 2013, 373275

16. Kennedy, S. P., Ng, W. V., Salzberg, S. L., Hood, L., and DasSarma, S. (2001) Understanding the adaptation of Halobacterium species NRC-1 to its extreme environment through computational analysis of its genome sequence. Genome Res. 11, 1641-1650

17. Elcock, A. H., and McCammon, J.A. (1998) Electrostatic contributions to the stability of halophilic proteins. J. Mol. Biol. 280, 731-748

18. Mevarech, M., Frolow, F., and Gloss, L. M. (2000) Halophilic enzymes: proteins with a grain of salt. Biophys. Chem. 86, 155-164

19. Fukuchi, S., Yoshimune, K., Wakavama, M., Moriguchi, M., and Nishikawa, K. (2003) Unique amino acid composition of proteins in halophilic bacteria. J. Mol. Biol. 327, 347-357

20. Dym, O., Mevarech, M., and Sussman, J. L. (1995) Structural features that stabilize halophilic malate dehydrogenase from an archaebacterium. Science 267, 1344-1346

21. Nayek, A., Sen Gupta, P. S., Banerjee, S., Mondal, B., and Bandyopadhyay, A. K. (2014) Salt-bridge energetics in halophilic proteins. PLoS One $\mathbf{9}$, e93862

22. Karshikoff, A., and Ladenstein, R. (2001) Ion pairs and the thermotolerance of proteins from hyperthermophiles: a "traffic rule" for hot roads. Trends Biochem. Sci. 26, 550-556

23. Chan, C. H., Yu, T. H., and Wong, K. B. (2011) Stabilizing salt-bridge enhances protein thermostability by reducing the heat capacity change of unfolding. PLoS One 6, e21624

24. Bergqvist, S., Williams, M. A., O'Brien, R., and Ladbury, J. E. (2003) Halophilic adaptation of protein-DNA interactions. Biochem. Soc. Trans. 31, 677-680

25. Bredenberg, J. H., Russo, C., and Fenley, M. O. (2008) Salt-mediated electrostatics in the association of TATA binding proteins to DNA: a combined molecular mechanics/Poisson-Boltzmann study. Biophys. J. 94, 4634-4645

26. Grötzinger, S. W., Alam, I., Ba Alawi, W., Bajic, V. B., Stingl, U., and Eppinger, J. (2014) Mining a database of single amplified genomes from Red Sea brine pool extremophiles-improving reliability of gene function prediction using a profile and pattern matching algorithm (PPMA). Front. Microbiol. 5, 134

27. Gasteiger, E., Hoogland, C., Gattiker, A., Duvaud, S., Wilkins, M. R. Appel, R. D., and Bairoch, A. (2005) Protein identification and 
analysis tools on the ExPASy server. In The Proteomics Protocols Handbook (Walker, J. M., ed), pp. 571-607, : Humana Press, Totowa, New Jersey

28. Yang, Z. R., Thomson, R., McNeil, P., and Esnouf, R. M. (2005) RONN: the bio-basis function neural network technique applied to the detection of natively disordered regions in proteins. Bioinformatics 21, 3369-3376

29. Lieutaud, P., Ferron, F., and Longhi, S. (2016) Predicting conformational disorder. Methods Mol. Biol. 1415, 265-299

30. Frege, T., and Uversky, V. N. (2015) Intrinsically disordered proteins in the nucleus of human cells. Biochem. Biophys. Rep. 1, 33-51

31. Lundberg, K. S., Shoemaker, D. D., Adams, M. W., Short, J. M., Sorge, J. A., and Mathur, E. J. (1991) High-fidelity amplification using a thermostable DNA polymerase isolated from Pyrococcus furiosus. Gene 108, 1-6

32. Lee, J. B., Hite, R. K., Hamdan, S. M., Xie, X. S., Richardson, C. C., and van Oijen, A. M. (2006) DNA primase acts as a molecular brake in DNA replication. Nature 439, 621-624

33. Van Oijen, A. M., Blainey, P. C., Crampton, D. J., Richardson, C. C., Ellenberger, T., and Xie, X. S. (2003) Single-molecule kinetics of lambda exonuclease reveal base dependence and dynamic disorder. Science 301, 1235-1238

34. Jergic, S., Horan, N. P., Elshenawy, M. M., Mason, C. E., Urathamakul, T., Ozawa, K., Robinson, A., Goudsmits, J. M., Wang, Y., Pan, X., Beck, J. L., van Oijen, A. M., Huber, T., Hamdan, S. M., and Dixon, N. E. (2013) A direct proofreader-clamp interaction stabilizes the Pol III replicase in the polymerization mode. EMBO J. 32, 1322-1333

35. Pandey, M., Elshenawy, M. M., Jergic, S., Takahashi, M., Dixon, N. E., Hamdan, S. M., and Patel, S. S. (2015) Two mechanisms coordinate replication termination by the Escherichia coli Tus-Ter complex. Nucleic Acids Res. 43, 5924-5935

36. Hamdan, S. M., Loparo, J. J., Takahashi, M., Richardson, C. C., and van Oijen, A. M. (2009) Dynamics of DNA replication loops reveal temporal control of lagging-strand synthesis. Nature 457, 336-339

37. Elshenawy, M. M., Jergic, S., Xu, Z. Q., Sobhy, M. A., Takahashi, M., Oakley, A. J., Dixon, N. E., and Hamdan, S. M. (2015) Replisome speed determines the efficiency of the Tus-Ter replication termination barrier. Nature 525, 394-398

38. Hashimoto, H., Nishioka, M., Fujiwara, S., Takagi, M., Imanaka, T., Inoue, T., and Kai, Y. (2001) Crystal structure of DNA polymerase from hyperthermophilic archaeon Pyrococcus kodakaraensis KOD1. J. Mol. Biol. 306, 469-477

39. Kim, S. W., Kim, D. U., Kim, J. K., Kang, L. W., and Cho, H. S. (2008) Crystal structure of Pfu, the high fidelity DNA polymerase from Pyrococcus furiosus. Int. J. Biol. Macromol. 42, 356-361

40. Lanyi, J. K. (1974) Salt-dependent properties of proteins from extremely halophilic bacteria. Bacteriol. Rev. 38, 272-290

41. Madern, D., Ebel, C., and Zaccai, G. (2000) Halophilic adaptation of enzymes. Extremophiles 4, 91-98

42. Evilia, C., Ming, X., DasSarma, S., and Hou, Y. M. (2003) Aminoacylation of an unusual tRNA(Cys) from an extreme halophile. RNA 9, 794-801

43. Evilia, C., and Hou, Y. M. (2006) Acquisition of an insertion peptide for efficient aminoacylation by a halophile tRNA synthetase. Biochemistry 45, 6835-6845

44. Taupin, C. M., Härtlein, M., and Leberman, R. (1997) Seryl-tRNA synthetase from the extreme halophile Haloarcula marismortuiisolation, characterization and sequencing of the gene and its expression in Escherichia coli. Eur. J. Biochem. 243, 141-150

45. Cacciapuoti, G., Fuccio, F., Petraccone, L., Del Vecchio, P., and Porcelli, M. (2012) Role of disulfide bonds in conformational stability and folding of $5^{\prime}$-deoxy-5'-methylthioadenosine phosphorylase II from the hyperthermophilic archaeon Sulfolobus solfataricus. Biochim. Biophys. Acta 1824, 1136-1143

46. Bergen, K., Betz, K., Welte, W., Diederichs, K., and Marx, A. (2013) Structures of KOD and $9^{\circ} \mathrm{N}$ DNA polymerases complexed with primer template duplex. Chembiochem 14, 1058-1062

47. Tuma, R., Russell, M., Rosendahl, M., and Thomas, G. J., Jr. (1995) Solution conformation of the extracellular domain of the human tumor necrosis factor receptor probed by Raman and UV-resonance
Raman spectroscopy: structural effects of an engineered PEG linker. Biochemistry 34, 15150-15156

48. Das, G., Mecarini, F., Gentile, F., De Angelis, F., Mohan Kumar, H., Candeloro, P., Liberale, C., Cuda, G., and Di Fabrizio, E. (2009) Nanopatterned SERS substrate: application for protein analysis vs. temperature. Biosens. Bioelectron. 24, 1693-1699

49. Das, G., Gentile, F., Coluccio, M. L., Perri, A. M., Nicastri, A., Mecarini, F., Cojoc, G., Candeloro, P., Liberale, C., De Angelis, F., and Di Fabrizio, E. (2011) Principal component analysis based methodology to distinguish protein SERS spectra. J. Mol. Struct. $\mathbf{9 9 3}$, 500-505

50. Greenfield, N. J. (2006) Using circular dichroism spectra to estimate protein secondary structure. Nat. Protoc. 1, 2876-2890

51. Karlin, S., Brocchieri, L., Bergman, A., Mrazek, J., and Gentles, A. J. (2002) Amino acid runs in eukaryotic proteomes and disease associations. Proc. Natl. Acad. Sci. USA 99, 333-338

52. Huyghues-Despointes, B. M., Scholtz, J. M., and Baldwin, R. L. (1993) Effect of a single aspartate on helix stability at different positions in a neutral alanine-based peptide. Protein Sci. 2, 1604-1611

53. Costantini, S., Colonna, G., and Facchiano, A. M. (2006) Amino acid propensities for secondary structures are influenced by the protein structural class. Biochem. Biophys. Res. Commun. 342, 441-451

54. Sinha, R., and Khare, S. K. (2014) Protective role of salt in catalysis and maintaining structure of halophilic proteins against denaturation. Front. Microbiol. 5, 165

55. Siamwiza, M. N., Lord, R. C., Chen, M. C., Takamatsu, T., Harada, I., Matsuura, H., and Shimanouchi, T. (1975) Interpretation of the doublet at 850 and $830 \mathrm{~cm}-1$ in the Raman spectra of tyrosyl residues in proteins and certain model compounds. Biochemistry 14, $4870-4876$

56. Li-Chan, E., Nakai, S., Hirotsuka, M. (1994) Raman Spectroscopy as a Probe of Protein Structure in Food System, Blackie Academic E Professional. Chapman and Hall, London

57. Hecht, K., Wrba, A., and Jaenicke, R. (1989) Catalytic properties of thermophilic lactate dehydrogenase and halophilic malate dehydrogenase at high temperature and low water activity. Eur. J. Biochem. 183, 69-74

58. Fiala, G., and Stetter, K. O. (1986) Pyrococcus-furiosus sp-nov represents a novel genus of marine heterotrophic Archaebacteria growing optimally at 100-degrees C. Arch. Microbiol. 145, 56-61

59. Morikawa, M., Izawa, Y., Rashid, N., Hoaki, T., and Imanaka, T. (1994) Purification and characterization of a thermostable thiol protease from a newly isolated hyperthermophilic Pyrococcus sp. Appl. Environ. Microbiol. 60, 4559-4566

60. Santos, H., and da Costa, M. S. (2002) Compatible solutes of organisms that live in hot saline environments. Environ. Microbiol. 4, 501-509

61. Terpe, K. (2013) Overview of thermostable DNA polymerases for classical PCR applications: from molecular and biochemical fundamentals to commercial systems. Appl. Microbiol. Biotechnol. 97, 10243-10254

62. Tabor, S., and Richardson, C. C. (1989) Effect of manganese ions on the incorporation of dideoxynucleotides by bacteriophage T7 DNA polymerase and Escherichia coli DNA polymerase I. Proc. Natl. Acad. Sci. USA 86, 4076-4080

63. Xue, B., Williams, R. W., Oldfield, C. J., Dunker, A. K., and Uversky, V. N. (2010) Archaic chaos: intrinsically disordered proteins in Archaea. BMC Syst. Biol. 4(Suppl 1), S1

64. Madern, D., Camacho, M., Rodríguez-Arnedo, A., Bonete, M. J., and Zaccai, G. (2004) Salt-dependent studies of NADP-dependent isocitrate dehydrogenase from the halophilic archaeon Haloferax volcanii. Extremophiles 8, 377-384

65. Vieille, C., and Zeikus, G. J. (2001) Hyperthermophilic enzymes: sources, uses, and molecular mechanisms for thermostability. Microbiol. Mol. Biol. Rev. 65, 1-43

66. Wu, F. Y., and Wu, C. W. (1987) Zinc in DNA replication and transcription. Annu. Rev. Nutr. 7, 251-272

Received for publication August 21, 2017. Accepted for publication January 16, 2018. 